\title{
CERROS, UNA VISIÓN DEL PRECLÁSICO TARDÍO MAYA
}

\author{
SUZANNE LEWENSTEIN \\ Universidad de las Américas
}

\section{Introducción}

Los descubrimientos e investigaciones arqueologicas en la zona maya, durante los últimos 15 años, nos han aportado una amplio panorama en muchos aspectos de la historia de aquella cultura, y de los procesos evolutivos que operaron para su desarrollo (Adams 1986, Dahlin 1984, Shafer y Hester 1984, Freidel 1979, Freidel y Schele 1988b, MacNeish 1981). Sobre todo, ahora contamos con mayor información sobre los inicios de la civilización maya. Se reconoce que al menos en Belice el Preclásico empieza con aldeas permanentes y estructuras públicas presentes en la etapa media de este periodo. Por la distribución de artefactos de jade, también se observa la penetración estilística de los olmecas en las tierras bajas mayas durante el Preclásico medio y tardío, tanto en la costa del Paćfico, como en la cuenca del Usumacinta y en Belice (Hammond 1982). Nuevos datos arquitectónicos e iconográficos constatan que los inicios de la complejidad cultural que antes se atribuyó al periodo Clásico, realmente se desarrolló más temprano, e in situ dentro de las tierras bajas, durante el Preclásico Medio y Tardío (Pendergast 1981, Freidel 1981, Hammond 1982). Además hemos visto avances significativos en la investigación acerca de la subsistencia maya. Últimamente ha quedado claro que a partir de tiempos preclásicos, los mayas en las tierras bajas empezaron a 
experimentar con las técnicas para la intensificación agrícola. Construyeron campos agrícolas levantados o camellones, canales y zanjas de drenaje, terrazas sobre terrenos con pendiente, y reservorios para captar y almacenar agua durante épocas de sequia (Ochoa y Vargas 1985, Puleston 1978, Harrison y Tumer 1978). Sobre todo, estos nuevos datos fueron resultado de una proliferacion de investigaciones a largo plazo, tanto trabajos en el campo como detallados análisis de los materiales recuperados, de la iconografia y de las relaciones hombre-medio ambiente. De hecho, estos proyectos siguen dando resultados aun muchos años después de haberse concluido los trabajos de campo.

Consideramos que el Proyecto Cerros es un ejemplo de una investigación de campo que ha marcado la pauta para modificar y profundizar nuestro conocimiento del desarrollo maya. El Proyecto se inició en 1974. Después de sus investigaciones sobre el Postclásico en Cozumel, David Freidel fue invitado a investigar un sitio maya, supuestamente Postclásico, en la costa septentrional de Belice. Durante la primera temporada de campo Freidel se dio cuenta de que Cerros no era un sitio tardío, sino una comunidad que había tenido una fuerte ocupación durante la fase Chicanel, con una ligera presencia posterior, en el Postclásico Tardío (Freidel 1986). Después se averiguó que toda la arquitectura monumental y casi toda la construcción doméstica se fechaban dentro del Preclásico Tardío. Para aprovechar el acceso a un sitio temprano que no estaba cubierto de construcciones posteriores, se modificaron los objetivos del proyecto, esto se hizo con el fin de estudiar este fenómeno tan raro, es decir, una comunidad maya preclásica casi intacta. Por fortuna el sitio habŕa sufrido poco saqueo, debido a su ubicación beliceña, dentro de una zona aislada, casi despoblada e inaccesible por vehículo. De hecho, las únicas alteraciones notables eran, la aparente destrucción de algunas unidades habitacionales al suroeste del sitio, cuando se instaló una pequeña pista aérea, y cierto acarreo de piedras de la estructura 5B, montículo ubicado en la costa, a la cual los moradores actuales de la península suelen visitar en lancha cuando les hacen falta materiales de construcción en su pueblo. 
Durante siete años los integrantes del Proyecto Cerros investigamos el sitio, realizando un mapa de la comunidad precolombina (Figura 1), levantamientos de las estructuras principales, y de las obras hidraulicas. Además se excavaron calas de sondeo y aperturas horizontales, tanto en los monumentos ć́vicos como en muchas de las unidades habitacionales de Cerros. Se establecio asf la secuencia cerámica y una secuencia de tres fases consecutivas de construcción y ocupación doméstica durante el Preclásico Tardío (Robertson-Freidel 1980). Posteriormente a los trabajos de campo, se realizaron varios analisis extensivos en tomo a diversos aspectos de la investigacion, que dieron como fruto seis tesis de doctorado terminadas, y dos más que se encuentran en preparacion.

Un descubrimiento sobresaliente fue el hallazgo de tres estructuras cívicas que llevan fachadas decoradas con mascarones estucados. Además, encima de uno de los monumentos principales se encontro una ofrenda que contenía una colección de cinco cabezas de jade, las cuales evidencian rasgos olmecas, y además sugieren una forma inicial del dios "arlequín", símbolo del acceso al poder de los reyes mayas durante el subsecuente periodo Clásico (Freidel y Schele 1988a, b). También llama la atención el hallazgo de un largo canal de drenaje que circunda el sitio y que puede ser el más antiguo conocido en las tierras bajas mayas. Ligado al canal los mayas construyeron un sistema de camellones agrícolas. En lo que se refiere a la incipiente jerarquización de esta sociedad preclásica, es significativo el descubrimiento de dos juegos de pelota, los cuales representan una rareza en tiempos preclásicos tardíos. Además, abundan las evidencias arquitectónicas e iconográficas, que indican una transformación rápida y profunda en la sociedad de Cerros durante el último siglo antes de Cristo.

Como consecuencia de la acumulación de nueva información en el área maya, y especialmente como resultado de investigaciones que aún continúan con respecto al sitio de Cerros, intento aquí una breve síntesis de lo que se conoce actualmente sobre este sitio y sus aportaciones a la arqueología del Preclásico Tardío en las tierras bajas mayas. El énfasis no se hará en Cerros, como una ano- 


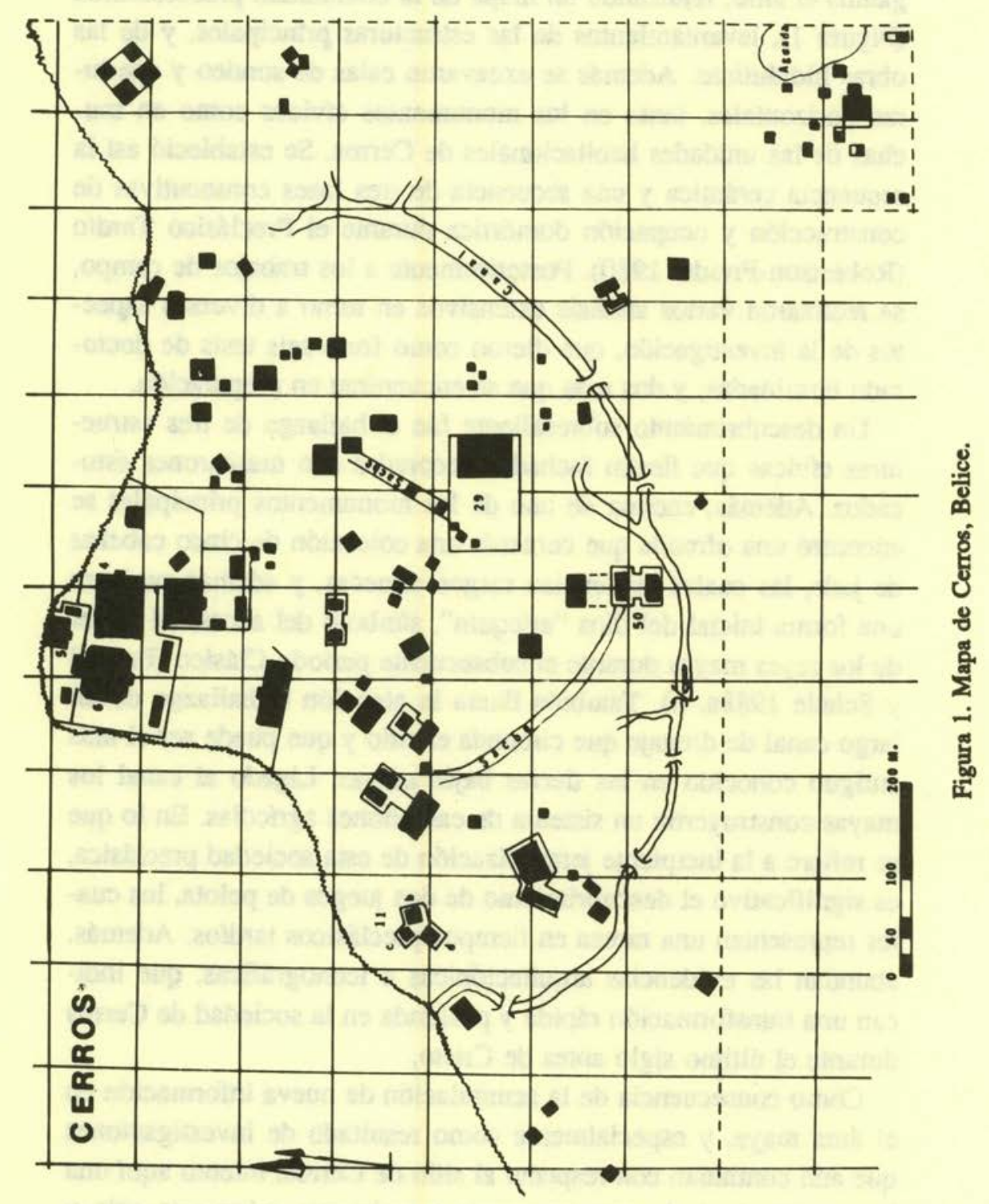


malía durante el Preclásico, sino como un ejemplo fortuito de los procesos de evolución social y política de la civilización maya, que se desarrollaron en una gran parte de su territorio antes del segundo siglo de nuestra era. En fin, el fenómeno de Cerros se puede considerar como una ventana por la cual podemos observar la evolución de varias instituciones a nivel regional.

\section{El medio ambiente y su aprovechamiento}

por los habitantes del Preclásico de Cerros

Las ruinas de Cerros se ubican en la costa meridional de la Bahía de Corozal, en una pequeña península pantanosa que no rebasa una elevación de 5 metros sobre el nivel del mar (Figura 2). En la actualidad la vegetación clímax en las áreas mejor drenadas consiste en una diversidad de árboles, como el zapote (Achras zapota), la caoba (Swietenia macrophylia), el cedro (Cedrela mexicana), y el siricote (Cordia dodecandra), los cuales alcanzan una altura de $25 \mathrm{~m}$. en este medio ambiente (Lewenstein 1987, Scarborough 1980). Estas especies, sin duda, fueron explotadas para la elaboración de cayucos, para obras de construcción, y para la manufactura de recipientes y figuras talladas, artefactos que exigen maderas duras y finas (Lewenstein 1982). En las zonas recién taladas, se nota una canopia arboral de pereskkuch (Croton reflexifolius), chechem (Metopium browneii), chacah (Bursera simaruba), pixoy (Guazuma ulmifolia) y huano (Sabal mayarum). En Cerros, como en otras partes de la zona maya, el árbol que crece con más frecuencia sobre las ruinas es el ramon (Brosiumum alicastrum). Se desconoce si su frecuente asociación con sitios arqueológicos en la región se deba a la preferida explotación por los mayas de la antigüedad, o simplemente a las condiciones optimas que le ofrece un asentamiento abandonado (Puleston 1978, Lambert y Amason 1978). Como en casi toda la península yucateca, el sustrato es de roca madre caliza. Por su baja elevación y situación ribereña, la zona tiene problemas estacionales de drenaje, lo que resulta, en los 
lugares de baja elevacion, en manchas de sabanas donde abundan los zacates. Los suelos supuestamente se califican como "mediocres" para la explotación agricola (Wright y otros 1959:63). En comparación con el resto de Belice, el clima aqui en el norte se

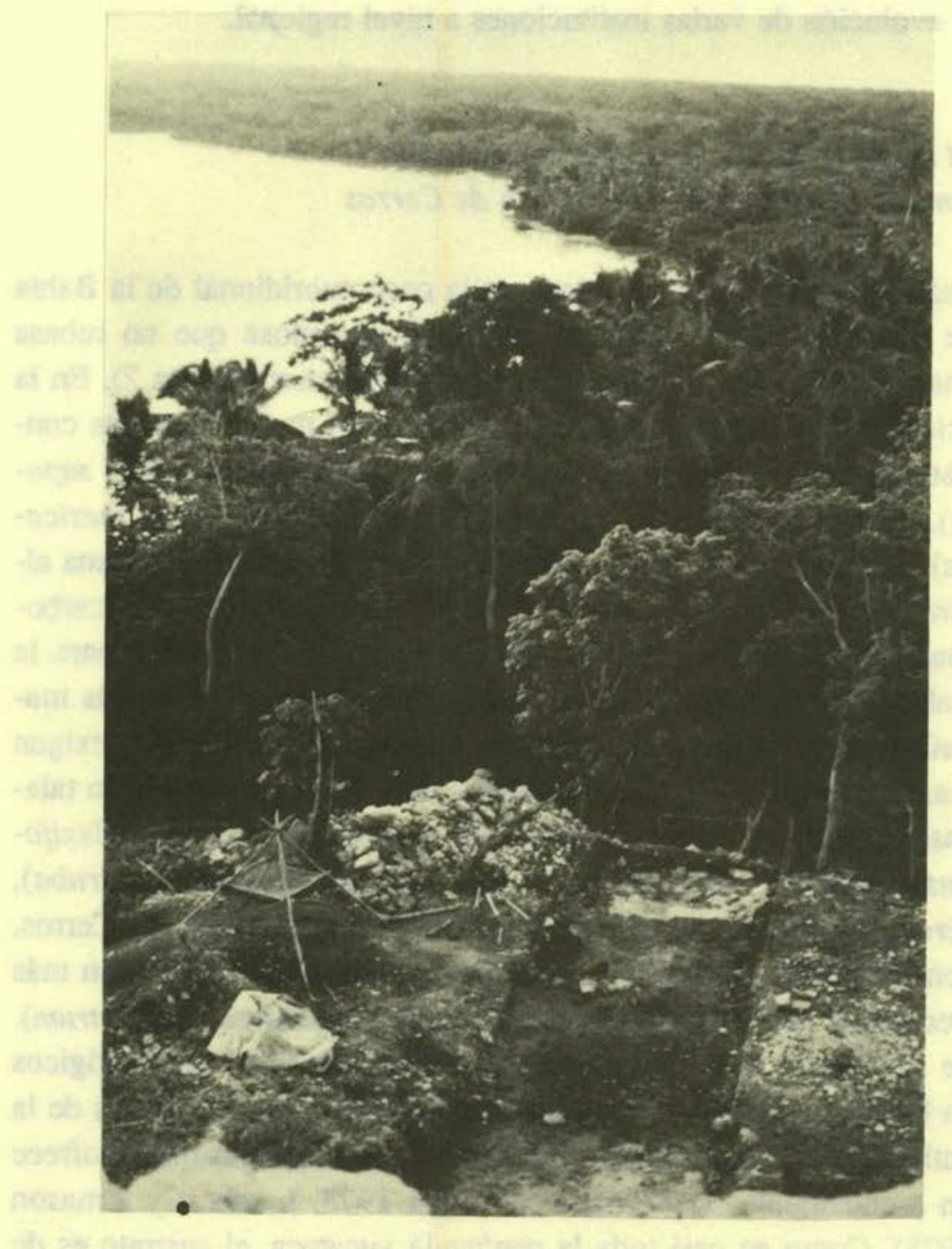

Figura 2. Vista de Cerros: la plaza y la zona del caserío pionero, tomada desde la cumbre de la Estructura 4B. 
caracteriza por ser relativamente seco, es decir, se trata del llamado bosque tropical seco, que cuenta con s6lo $152 \mathrm{~cm}$ de lluvia anual. La precipitación se concentra en un periodo de 3 meses, durante el cual el sitio sufre de inundaciones y de una abundancia increfble de mosquitos.

Como consecuencia de su situación geográfica ribereña, Cerros particip6 en una red de comercio marítimo durante los tiempos preclásicos. Estas actividades comerciales se conocen por la distribución de cerámica y de otros bienes, los que sirven como elementos de diagnostico de su lugar de origen. Durante aquellos tiempos tempranos se establecí una ruta comercial por la costa, que llego al norte hasta Komchen, en la planicie costera septentrional yucateca. Rumbo al sur, se extendio hasta Honduras (Freidel 1976, 1978). Cerros importo sal del norte; del sur consiguí los implementos para la molienda hechos de cuarcita, materia prima que se encuentra en las Montañas Mayas del Belice occidental, a unos $150 \mathrm{~km}$. Otras manos y metates de riolita y andesita tienen su origen a unos $400 \mathrm{~km}$, en el sur de Guatemala (Sidrys y Andresen 1976), igual que el jade, la hematita y la obsidiana, que llegaron a Belice septentrional por lancha: primero se transportaban rio abajo hasta el mar, y luego rumbo al norte, como un elemento más del comercio marítimo en el que participaba Cerros (Garber 1986).

A unos pocos kilómetros del oeste de Cerros se encuentra la boca del Río Hondo, que sirvió como carretera al interior hasta el Petén, en Guatemala. Supuestamente, Cerros funciono como nudo vital en la red de comunicación y comercio entre el Caribe y la zona maya nuclear. Además, a nivel local, Cerros mantuvo contactos comerciales con otras comunidades coetáneas en Belice, como son: Colha, Lamanai, Cuello y los sitios en el pantano Pulltrouser, entre otros. Ello, por cierto, vía lancha, a través del sistema de rós y lagunas que dan al interior del país (Freidel 1978).

Para poder adaptarse durante 400 años a este medio ambiente de disponibilidad tan variable de lluvias, los mayas preclásicos de Cerros perfeccionaron un sistema para captar y almacenar agua. Al 
principio los moradores solo aprovecharon las dos aguadas naturales en sus alrededores; luego, debido a la expansión demográfica durante el segundo siglo a.c., construyeron un gran canal de drenaje, el que mide $1200 \mathrm{~m}$ de longitud, y circundaba la zona residencial del sitio (Freidel y Scarborough 1982, Scarborough 1983). Este canal, supuestamente una obra hidráulica para el abastecimiento público, ayudó durante las épocas de lluvia a drenar los terrenos agrícolas, y a almacenar y dirigir el flujo de aguas superficiales. Dentro de la zona comprendida por el canal se hallaron varias zanjas y canales laterales, que canalizaron aguas hacia y desde el canal principal.

También fue alli donde los mayas prepararon un área de aproximadamente una hectárea de camellones, o terrenos levantados. Los camellones extienden el área disponible para cultivar a las zonas con mal drenaje natural (Dahlin 1985). Los campos levantados miden hasta unos 22 x $40 \mathrm{~m}$. Las zanjas limitrofes se llenaban durante las épocas de lluvia, y así pudieron mantener húmedas las parcelas elevadas. Durante las sequías los camellones probablemente fueron alimentados por riego de cántaro (Rojas 1985). Además, en el lado este de los camellones se excavaron tres reservorios, dos de ellos separados de los camellones por un sacbé, o camino levantado, lo que permitio la acumulación y almacenaje de agua potable, separada del agua de riego, que fluía por las zanjas que rodearon y delimitaron los camellones. Quizá, estos depositos sirvieron como reservas privadas para las satisfacción de la demanda de ciertas familias de la élite que habitaron justo al este del sacbé, quienes almacenarían agua potable durante epócas de lluvia, para su consumo durante las sequías (Scarborough 1983).

Una serie de análisis de suelos y materiales orgánicos, como huesos faunísticos, semillas carbonizadas y otros restos vegetales, aunada a los estudios del polen arqueologico, nos ha proporcionado datos referentes a la subsistencia preclásica de Cerros. Sobre todo, recuperamos muchas evidencias florísticas mediante la flotación de más de 300 muestras de suelo, colectadas de la zona de la aldea pionera, a lo largo de la costa (Crane 1986). Con base en 
esto se plantea un sistema de agricultura de roza con maíz, el alimento preferido, suplementado por frijoles, y calabazas (Crane 1986). Adicionalmente, la distribución espacial de los montículos bajos sugiere el cultivo de huertos familiares, además de las milpas, o campos exteriores (Dahlin 1985, Puleston 1978). Estas huertas se caracterizan por su gran diversidad de especies, entre las que se incluyen las hierbas y plantas medicinales, los chiles y jitomates, los árboles frutales, el nogal, y las rafces comestibles como la jícama, el camote, y la yuca (Bronson 1965, Dahlin 1985).

Todavía no se ha determinado si los camellones sirvieron como terrenos para milpa intensiva o para el cultivo de productos comerciales como el cacao o el algodón. Los mayas en algunas áreas y épocas se especializaron en estas especies económicas, y a pesar de consumirlas dentro del pueblo, las exportaron a otras partes, donde las condiciones ambientales no les permitran crecer (Dahlin 1979). En Cerros se hallaron restos de fibras de algodón en forma de fragmentos de textiles asociados con un entierro preclásico (Cliff 1982). También se ha detectado una ligera presencia de cacao entre los materiales vegetales analizados (Crane 1986). Actualmente el cacao no crece en Belice septentrional. Por lo tanto, surge la pregunta, ¿fue sembrado alli, o fue importado al sitio? Seguramente los pobladores de Cerros aprovecharon los productos del bosque, la fruta del ramón y de la palma cocoyal, el nance, y del siricote. Esta explotación es aparente por la frecuencia tan alta con que los restos de sus frutos fueron recuperados en los basureros domésticos de Cerros (Crane 1986).

Cabe decir que la zona de aprovechamiento incluyó varios nichos ambientales: el bosque, la sabana, la costa del Caribe, y probablemente también la boca del Río Nuevo, con su agua dulce y su franja de manglares. También se plantea la explotación del mar y de los cayos beliceños por la presencia de un muelle (malecón de cascote) asociado con la segunda fase de la ocupación costera (Cliff 1988), y por la recuperación de abundantes especies de fauna maritima, incluyendo el caracol del mar (Carr 1986). 
De hecho, los habitantes de Cerros se orientaron hacia el mar en la mayor parte de su cacería, según la proporción tan alta de especies acuáticas $(77 \%)$ identificadas en la colección de fauna (Carr 1986). Evidentemente se explotaron las zonas costeras maritimas, también las medias ribereñas, y el mar profundo. En cuanto a la captura de proteínas, los moradores de Cerros comieron, principalmente, las tortugas de laguna y mar, los cangrejos, y peces, tales como la barracuda y la mojarra. Entre otras técnicas de pesca, las evidencias arqueologicas sugieren el uso de redes, por la elevada frecuencia de las llamadas "mariposas", o pesas de red de pesca en Cerros, que se elaboraron cortando muescas en los tepalcates y guijarros (Garber 1986:126; Lewenstein 1986). Las especies terrestres que se cazaban en Cerros comprenden al venado (Odocoileus virginianus, y Mazama americana), especies que habitan en monte bajo y que también frecuentan terrenos en barbecho, donde buscan de comer, además aprovecharon las tortugas por igual. Entre los huesos quemados también se observan restos de perros (Carr 1986). Se sospecha que los perros constituyeron el elemento alimenticio preferido durante el Preclásico Tardío (Harrison y Tumer 1978, Pohl y Feldman 1982, Wing 1981).

\section{Historia del asentamiento Preclásico en Cerros}

Lo más impresionante de la secuencia ocupacional de Cerros fue el tan rápido desarrollo cultural durante los tiempos Chicanel. Con base en la cerámica y en los episodios de construcción, se ha establecido una serie de 3 fases de ocupación preclásica, que inician con un caserío igualitario de pescadores agricultores. Este periodo inicial se ha designado Ixtabai (Figura 3). Dentro del primer siglo de ocupación en la costa del Caribe, Cerros creció demográficamente, y además se desarrollo, expandiendo su comunidad más allá de la franja costera, hasta el interior de la península. Durante la siguiente fase, C'oh, se iniciaron las primeras construcciones públicas, y también se excavó el canal de drenaje y el muelle a la 
entrada del sitio. Pero fue durante la fase Tulix cuando los moradores efectivamente decidieron destruir ritualmente su pueblo, y volver a construirlo a una escala monumental. También durante este periodo se presenta la evolución de un grupo élite, primero

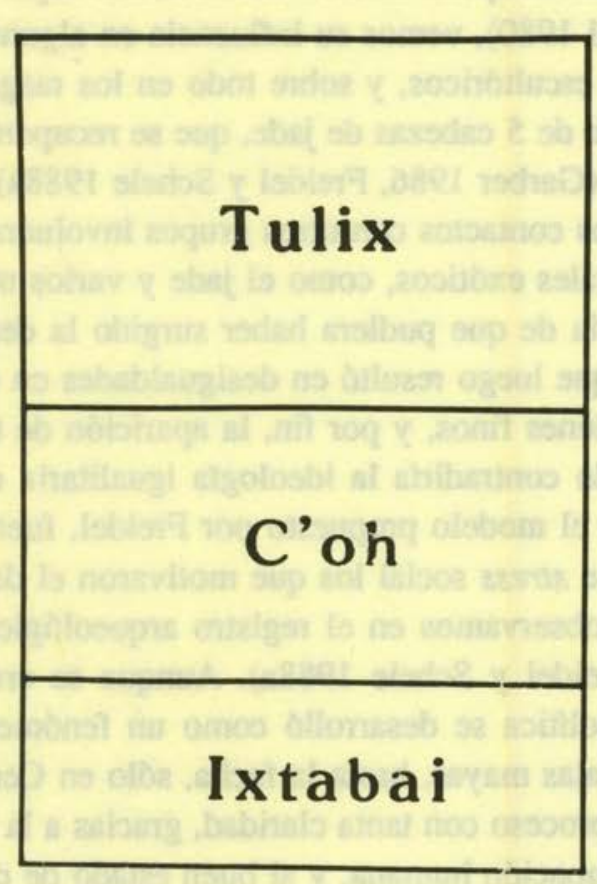

A.D. 150

50 B.C.

200 B.C.

300 B.C.

Figura 3. Secuencia preclásica de ocupación en Cerros. 
con base en la función religiosa, para después convertirse en una institución política (Freidel y Schele 1988a). Lo raro no es que todo ello haya sucedido, sino que ocurrio totalmente durante del periodo Preclásico Tardío, y que su desarrollo haya sido tan acelerado (Freidel y otros 1982).

Entre los factores que impulsaron este florecimiento cultural se incluyen el comercio y la comunicación con otros pueblos vecinos, a mediana y larga distancia. Destaca especialmente la influencia olmeca durante el Preclásico. Aunque los tiempos Tulix postfechan con cuatro siglos la época olmeca en las tierras bajas (Weaver 1981, Coe y Diehl 1980), vemos su influencia en algunos elementos iconográficos escultoricos, y sobre todo en los rasgos que manifiesta una ofrenda de 5 cabezas de jade, que se recupero en la pirámide 6 de Cerros (Garber 1986, Freidel y Schele 1988a).

Aparentemente estos contactos con otros grupos involucraron el intercambio de materiales exóticos, como el jade y varios minerales, como consecuencia de que pudiera haber surgido la demanda por lo importado, lo que luego resulto en desigualdades en cuanto a la distribución de bienes finos, y por fin, la aparición de tensiones sociales. Todo ello contradirfa la ideología igualitaria de una aldea pequeña. Según el modelo propuesto por Freidel, fueron los intentos por aliviar ese stress social los que motivaron el desarrollo sociopolítico que observamos en el registro arqueológico Preclásico de Cerros (Freidel y Schele 1988a). Aunque se cree que esta evolución sociopolítica se desarrollo como un fenómeno regional en las tierras bajas mayas, hasta la fecha, solo en Cerros se puede documentar el proceso con tanta claridad, gracias a la carencia de subsecuente ocupación humana, y al buen estado de conservación del sitio.

Los primeros indicios de ocupación en Cerros corresponden a la fase Ixtabai, que data entre 300-200 a.c. Los restos de esta fase están distribuidos a lo largo de la costa. Se han descubierto 12 estructuras, las que posteriormente fueron enterraradas por debajo de la construcción de una gran plaza (Cliff 1982, 1986). La aldea costera consiste en una serie de estratos superpuestos, hasta una 
profundidad de $1 \mathrm{~m}$. Se dio a conocer por la erosión ribereña, la que expuso un perfil en el que se vera una serie de pisos, con sus múltiples episodios de reparación y renovacion, y hasta entierros expuestos. Este perfil se prolonga unos $65 \mathrm{~m}$ al este de la zona de arquitectura ćvica y por debajo de la plaza principal de Cerros (Figura 4). Cabe mencionar que el hallazgo de tantas capas superpuestas no necesariamente refleja un largo periodo de ocupación. En la actualidad las chozas tradicionales de bajareque (palos y paja) se modifican cada 5-10 años, según estudios de los mayas kekchr actuales en Belice meridional (Wilk 1983).

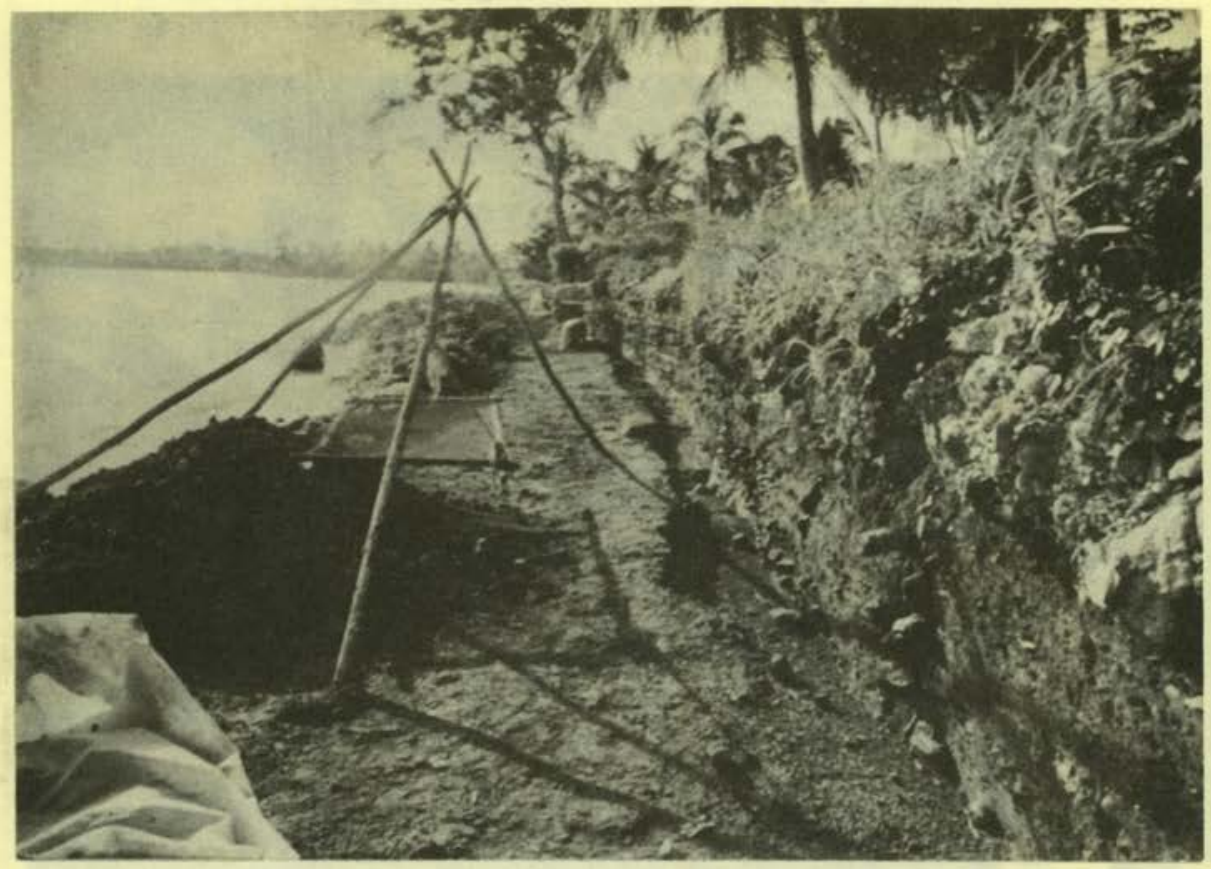

Figura 4. El perfil de la aldea pionera en la costa de Cerros. Vista este. 
Este asentamiento pionero contaba con pocas viviendas, que siempre fueron construidas sobre el nivel natural de la tierra, es decir, se trata de aquellas unidades habitacionales "invisibles" que eluden a los arquélogos, por no ser identificables en la superficie. En general, carecen de una plataforma o acumulación de materiales de construcción. La arquitectura doméstica se interpreta como reflejo de la organización social de una comunidad. De alguna manera cada vivienda sugiere la posición social de sus habitantes. Juntas, las unidades habitacionales reflejan la estructura social que vive un pueblo (Cliff 1988:202). Durante la fase Ixtabai, los moradores de Cerros prepararon los pisos de sus viviendas con arcillas quemadas, mientras que algunos de los patios exteriores se acabaron con estuco (Figura 5). No se distingue ninguna evidencia de

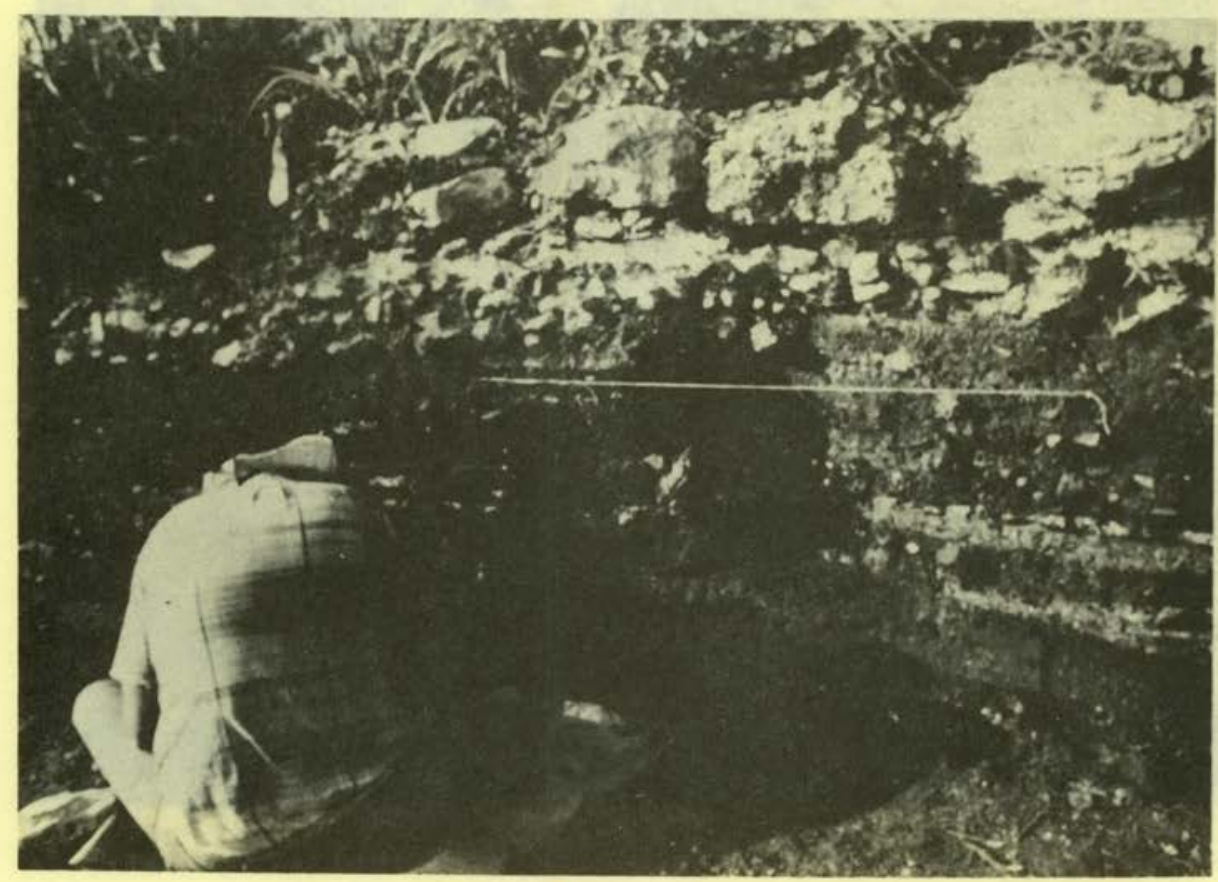

Figura 5. Sección del perfil costero, muestreando dos pisos, debajo del nivel de la plaza. 
agrupación de estructuras domésticas, como se nota posteriormente en el patrón típico de asentamiento maya. Tampoco se identifico ningún ejemplo de arquitectura pública en esta aldea formativa. Todas las evidencias indican una comunidad igualitaria. Además del número reducido de chozas en la costa, el único otro indicio de ocupación Ixtabai en Cerros consiste en las concentraciones de tepalcates al lado de una aguada natural que se ubica a un kilometro y medio al sur del resto del asentamiento. La extensión de Ceros durante tiempos Ixtabai se estima en un máximo de 2 hectáreas, quizá con unos habitantes (Cliff 1988, Lewenstein 1987:147-8).

No cabe duda que la cerámica Ixtabai pertenece a la esfera Chicanel que se encuentra por todas las tierras bajas mayas. Se notan filiaciones estilísticas y tecnologicas entre los tipos en Cerros y la alfarería de otros sitios contemporáneos en Belice septehtrional, y con sitios más lejanos, como son Barton Ramie, Uaxactún, Becán y el norte de Yucatán (Robertson 1986). Especialmente destacan el grupo Sierra Rojo, los acabados cerosos, y la baja frecuencia de decoración. En cuanto a la lítica Ixtabai, solo un 7\% de los instrumentos fueron elaborados de obsidiana, en forma de navajillas prismáticas, que siempre, durante el Preclásico Tardío, venf́a del yacimiento guatemalteco de El Chayal. El resto de la piedra tallada es de sflex procedente de los talleres de Colhá, a una distancia de $30 \mathrm{~km}$ al sur de Cerros (Hester y Shafer 1984). Lo curioso de los artefactos líticos es la relativamente alta proporción, en contraste con las fases subsecuentes, de herramientas formales, es decir retocadas en formas estandarizadas. Ello sugiere la especialización artesanal por parte de los lasqueadores de Colhá, a partir de por lo menos tres siglos antes de Nuestra Era. Se ve también, la costumbre de reciclar las herramientas rotas, convirtiendo asi una forma convencional en otro implemento menos estandarizado, muchas veces con otra función (Lewenstein 1987). En fin, ni las técnicas de construcción ni los artefactos del periodo Ixtabai demuestran un nivel crudo o burdo. Todo se encuentra bien desarrollado y elaborado; sólo se trata de una comunidad pequeña y todavía no jerarquizada, en donde habitaron agricultores, los que también se orientaron hacia el mar para su subsistencia. 
C'oh, la fase siguiente, está fechada entre 200-50 a.c. Se nota un crecimiento demográfico de $400 \%$, con 3 concentraciones de residencias:

-en la costa, la cual representa una continuación de la ocupación Ixtabai ra 9 ,

$-250 \mathrm{~m}$ al oeste del caserío pionero, por debajo de la estructu-

- y al sur del asentamiento original, y dispersa por toda la zona comprendida dentro del canal.

Quizá esta expansión de la comunidad refleje 3 vecindarios, que pueden corresponder a 3 linajes distintos (Cliff 1988).

Las primeras unidades habitacionales en la zona de asentamiento disperso, también se construyeron al mismo nivel de la tierra, is decir, sin basamentos.

C'oh representa un periodo de muchos cambios en Cerros. Sobre todo destaca el inicio de la construcción pública, como por ejemplo, el malecón de cascote (el muelle) en la costa, y el canal de drenaje que circundaba la zona de residencia rural. Luego, empezaron a experimentar con la agricultura intensiva, construyendo una serie de campos levantados, o camellones agrícolas. En la costa, al lado del caserfo pionero, erigieron un pequefio basamento para el primer templo (Cliff 1986). Fue durante aquellos tiempos cuando por primera vez se ocupaba la zona periférica, o rural, donde subsecuentemente se construyó el juego de pelota (estructura 61). Es posible que primero este lugar haya sido usado como vivienda, al nivel de la tierra, y que después se convirtiera en una construcción sagrada.

En este periodo C'oh los mayas empezaron a ampliar sus técnicas constructivas, edificando algunas de sus estructuras sobre basamentos de arcilla, con una altura hasta de $15-20 \mathrm{~cm}$. Plantea Cliff que las primeras plataformas para viviendas se elaboraron con el fin de elevar las casas nuevas a la misma altura que tenían las demás, las que iban levántandose por la simple acumulación de materiales y por sucesivas modificaciones de la misma estructura. De hecho se elevaron plataformas, no para llamar la atencion a las 
diferencias sociales, sino para mantener el statu quo, o la aparencia de igualdad entre los aldeanos (Cliff 1988:207). Asf intentaron mantener los valores igualitarios dentro de la comunidad. Pero esta estrategia de nivelar físicamente a la gente, dio por resultado diferencias siempre más grandes en cuanto a la inversión laboral para la construcción de plataformas domésticas. A pesar de todo esfuerzo para negarlo, en los tiempos C'oh van surgiendo las primeras evidencias de desigualdad en Cerros.

Se han encontrado ofrendas dedicatorias por primera vez durante la fase C'oh, que significan la práctica de ceremonias privadas (Cliff 1988:207). También en los entierros de ese periodo se encuentran sugerencias de ritos familiares, y los inicios de ligeras diferencias en tomo al acceso a ciertos recursos económicos. Por ejemplo, destaca el caso de un entierro acompañado de artículos de jade y coral. Los dos materiales representan importación de larga distancia y, por lo tanto, una rareza dentro del pueblo. Aunque es evidente que algunos individuos disfrutaban de artículos de lujo, el consenso igualitario demandaba que se les dispusiera en depósitos "invisibles", como son los depósitos funerarios, situación opuesta al "consumo llamativo" de épocas subsecuentes.

En el transcurso de las décadas C'oh, la gente se acostumbraba, y toleraba cada vez más estas diferencias de acceso a bienes preferidos, y hasta soportaba cierta riqueza visible. Como consecuencia, se diversificó la arquitectura doméstica, tanto en la altura como en la elaboracion de sus basamentos, los que alcanzaron unos $30 \mathrm{~cm}$. También se nota más variabilidad en los materiales para la construcción, como la incorporación de pisos de sascab sobre grava. La comunidad siguio siendo un asentamiento disperso, sin planeación espacial.

En lo que se refiere al nivel doméstico, las viviendas se identifican por el tipo y la diversidad de artefactos cotidianos, como son la cerámica casera (Robertson 1983), la lítica, los malacates, y las mariposas, o sea, pesas para las redes de pesca. El desarrollo cerámico continúa con las tradiciones que se establecieron durante tiempos Ixtabai. El sitio aún sigue bastante vinculado con la cera- 
mica Chicanel del resto de las tierras bajas mayas. Las filiaciones más sobresalientes de la fase C'oh abarcan la ceramica de los sitios vecinos en el norte y el centro de Belice (Kosakowsky 1987, Gifford 1976, Pring 1977), El Petén (Smith 1955), y con Yucatán septentrional (Robertson 1986). Algunas innovaciones de la cerámica C'oh en Cerros incluyen la técnica decorativa trickle (chorreo), la técnica negativa de decorar una vasija con una serie de líneas curvilineales, o sea el llamado estilo Usulután, cuyo origen se encuentra en El Salvador. Los alfareros de Cerros produjeron una cerámica local, incorporando en ella diseños tipo Usulután Emplearon la técnica negativa, pero también elaboraron una versión de imitación, con una técnica positiva, es decir, aplicando la decoración por encima del engobe (Robertson-Freidel 1980). Por la homogeneidad en la distribución de los artefactos cotidianos, se plantea que Cerros aún gozaba de un espíritu de igualdad, a pesar de las incipientes diferencias económicas. Aparentemente, las emergentes diferencias economicas todavía no se habfan convertido en desigualidades sociales o políticas.

Al final de esta fase la comunidad de Cerros habra crecido hasta comprender unas 30 hectáreas, donde habitaron unas 400 personas. Aunque la comunidad mantuvo el ideal de la fratemidad igualitaria durante estos 150 años, la evolución de un sistema social igualitario, a uno más complejo y jerarquizado ya se había puesto en marcha.

El máximo desarrollo en Cerros ocurrió durante el periodo Tulix, entre 50 a.c. y 150 d.c. Fue entonces cuando aparecio la ceramica más fina del complejo Chicanel (Robertson 1986). La cerámica Tulix se destaca por su superioridad tecnologica, en virtud de que se cocía a temperaturas más altas, técnica no usada antes por los alfareros de Cerros. Dentro de esta fase se nota una diversificación de formas y decoraciones. El acabado ya no es ceroso, y a pesar del engobe rojo tradicional, ya se ha affadido un engobe anaranjado. Aparecen vasijas efigies y decoraciones cada vez más elaboradas. Sigue siendo popular la técnica negativa Usulután, aunque muchos otros elementos del mismo complejo Floral Park 
no se encuentran en la cerámica Tulix de Cerros. Aparentemente Cerros fue abandonado antes de desarrollarse por completo este complejo cerámico salvadorefio.

En lo referente a la lítica, la fase Tulix rindió proporcionalmente más obsidiana importada de las fuentes guatemaltecas. La mayoria de los implementos líticos, como en tiempos anteriores, fue elaborada de un sflex beliceño. Según la carencia de desechos de talla lítica registrados en el sitio, se plantea que Cerros importo sus herramientas líticas ya hechas del yacimiento y talleres de Colhá, a unos $30 \mathrm{~km}$ al sur, en Belice central (Hester 1985). Además de los instrumentos formales, es decir, retocados en ciertas formas estandarizadas, la mayoría de los implementos líticos consistieron en herramientas casuales, como lascas sin modificación o piezas agotadas pero recicladas.

Se notan cambios de organización de la comunidad, por la nueva costumbre de agrupar a las viviendas sobre plataformas y orientarlas con referencia a una plaza central. Un grupo residencial integra de una hasta cuatro viviendas que comparten una plataforma central (Ashmore 1981). En estas agrupaciones de unidades habitacionales, ahora se distinguen diferencias más fuertes en su calidad y su tamaño. Quizá esto refleje las diferentes posiciones socioeconómicas, que ya no se pueden negar, ni ocultar. Las técnicas de construcción siguen desarrollándose, con la agregación de basamentos de piedra, y de patios bien elaborados y acabados. Concentraciones de viviendas pueden corresponder a los varios linajes o grupos familiares. Identificamos 21 grupos de unidades habitacionales, que se fechan en la fase Tulix, s6lo en la zona de residencia dispersa, es decir fuera de la franja costera (Scarborough y Robertson 1986).

En lo referente a la construcción doméstica, ya no se usa la tierra quemada en la preparación de pisos, sino el estuco o el yeso. Varfan mucho las dimensiones de los patios exteriores de las unidades habitacionales. Las viviendas ya se diversifican, por su tamaño, y además por contar con múltiples cuartos.

Por aquellos tiempos, ya vemos establecidas claras diferencias 
de rango. Se pueden distinguir residencias de la gente común, y de las élites. La vivienda regular generalmente no es elevada sobre un basamento especial, no lleva patio particular ni cocina separada. Entre los artefactos se encuentran bajas frecuencias de la cerámica final. En contraste, las viviendas de las élites se construyeron de los mismos materiales perecederos, pero ahora sobre un basamento preparado. Muchas llevan su cocina separada, atrás de la residencia, y hasta cuentan con un amplio patio elevado. Además, en el caso de estas viviendas, se encuentra asociada bastante cerámica ceremonial.

Coetáneo con este desarrollo en la arquitectura doméstica, los habitantes de Cerros construyeron una pirámide chica, con una altura de $2 \mathrm{~m}$ (Estructura 2) en la costa, al lado del asentamiento original (Cliff 1988). Esta estructura efectivamente representa el primer templo en Cerros, que sirví para ciertos ritos y ceremonias públicas. Poco después de la construcción de este templo, y por motivos desconocidos, la gente de Cerros decidio abandonar el sitio de su aldea pionera, y luego erigir por encima de sus restos una nueva comunidad. Este evento (el abandono de la aldea costera de pescadores) se ha documentado en un rito, igual que en la dispersión simultánea de la gente, tierra adentro, hasta rebasar los límites del canal. Los ritos de abandono de las viviendas incluyeron la dispersión de una capa de sascab (cal blanca descompuesta) por encima de la zona residencial ya abandonada y del primer templo (Estructura 2). Además, quemaron las chozas ubicadas en la costa, y dispersaron fragmentos de ciertos artefactos intencionalmente rotos. Por ejemplo, se han encontrado debajo de la plaza, en esta zona costera, los fragmentos de cuentas de concha, jade, y cerámica, todo dentro de una capa de cenizas y sascab (Garber 1983). Todo esto fue resultado de un episodio cultural, durante el cual se sello el sitio ya abandonado (Garber 1986:116). Luego, encima de las ruinas se construyó la plaza principal de Cerros, elevada un metro sobre los restos del asentamiento anterior. Estos raros eventos sucedieron durante un periodo muy restringido en la historia de Cerros. De hecho, fue un momento decisivo en su desarro- 
1lo. Posteriormente observamos una expansión demografica y un surgimiento impresionante en la construcción de piramides, templos, y otros monumentos ć́vicos. Todo ello significa un cambio fuerte en la planeación arquitectónica, pero se llevó a cabo dentro de un marco de continuidad demográfica. Vemos un reemplazamiento de estructuras, sin inmigración de nuevos grupos de pobladores. En fin, seguian habitando alli los mismos habitantes de siempre. Se calcula que la comunidad de Cerros ocupo hasta 1 $\mathbf{k m}^{2}$ en tiempos Tulix. Durante esta fase quizá 1500 gentes radicaron en el pueblo (Lewenstein 1987, Scarborough1980)

\section{La secuencia arquitectónica de los monumentos principales}

Como ya hemos visto, a partir del 100 a.c. Cerros destaca por convertirse, durante un periodo muy corto, de un caserío rural de agricultores pescadores en un centro importante, a rafz de un esfuerzo concentrado en la construcción de monumentos de piedra (Freidel 1986). Esta conversión se llevó a cabo al principio como extensión de la aldea costeña, manifestándose primero en la erección de una plataforma pública con dimensiones basales de $16 \times$ $16 \mathrm{~m}$; más tarde se sobrepuso a este basamento un pequeño templo, que midió unos $2.3 \mathrm{~m}$ de altura, el llamado Estructura 24sub 4-primera. El fechamiento por carbono-14 indica una ocupación en 90 a.c. (s. $=50$ años) (Freidel 1986). Esta construcción lleva molduras basales, estucadas y pintadas en rojo. Corresponde a los inicios del desarrollo del centro ceremonial en Cerros. A este templo se le encontro en buenas condiciones de preservación por situarse debajo de la plaza principal del sitio. Después de una breve vida, menos de un siglo, el templo Estructura 2 y el caserío entero fueron destruidos ritualmente, y por encima fue dispersada una capa ligera de cenizas y sascab, en la cual se habran depositado gran cantidad de artefactos rotos, entre ellos piezas finas intencionalmente "matadas". Posteriormente, por encima se depositaron unos $3 \mathrm{~m}$ de cascotes de caliza, elevando así esta sección 




Figura 6. Montículo 5B, Cerros.

de costa, antes de construir la plaza principal que formaba la entrada del mar a la comunidad Tulix. Esta plaza formó parte integral del plan arquitectónico del centro ć́vico de Cerros. Al visitante, llegando por el mar, le ofrecía acceso tanto al área residencial como al recinto cívico. Fue precisamente en el límite occidental de esta gran plaza donde se construyó la acrópolis y el conjunto de monumentos públicos. El visitante podía acceder a los monumentos atravesando la plaza, y subiendo el basamento que daba a las pirámides 5, y 4 .

En el momento de levantar la plaza, los planeadores de Cerros erigieron un basamento y encima de éste construyeron una pirámide, la 5C-segunda (Figura 6). Se ubica sobre la extensión más occidental de la aldea anterior, que todavía se manifiesta en el nivel anterior con restos de viviendas perecederas y áreas de actividad, ubicadas sobre el nivel natural de la tierra. La 5C-segunda no se 
orienta al mar, sino en dirección opuesta, es decir al sur, y se accedía por la plaza, subiendo una escalinata central formal. Orientada a los dos lados de esta escalinata se encontraba una fachada decorada por una serie de mascarones de estuco, con la cual los mayas preclásicos de Cerros intentaron por primera vez expresar una ideología cosmologica que anunciara y justificara un orden jerárquico (Figura 7). Por encima del basamento y la pirámide 5Csegunda se descubrió una superestructura de mamposterfa, integra-

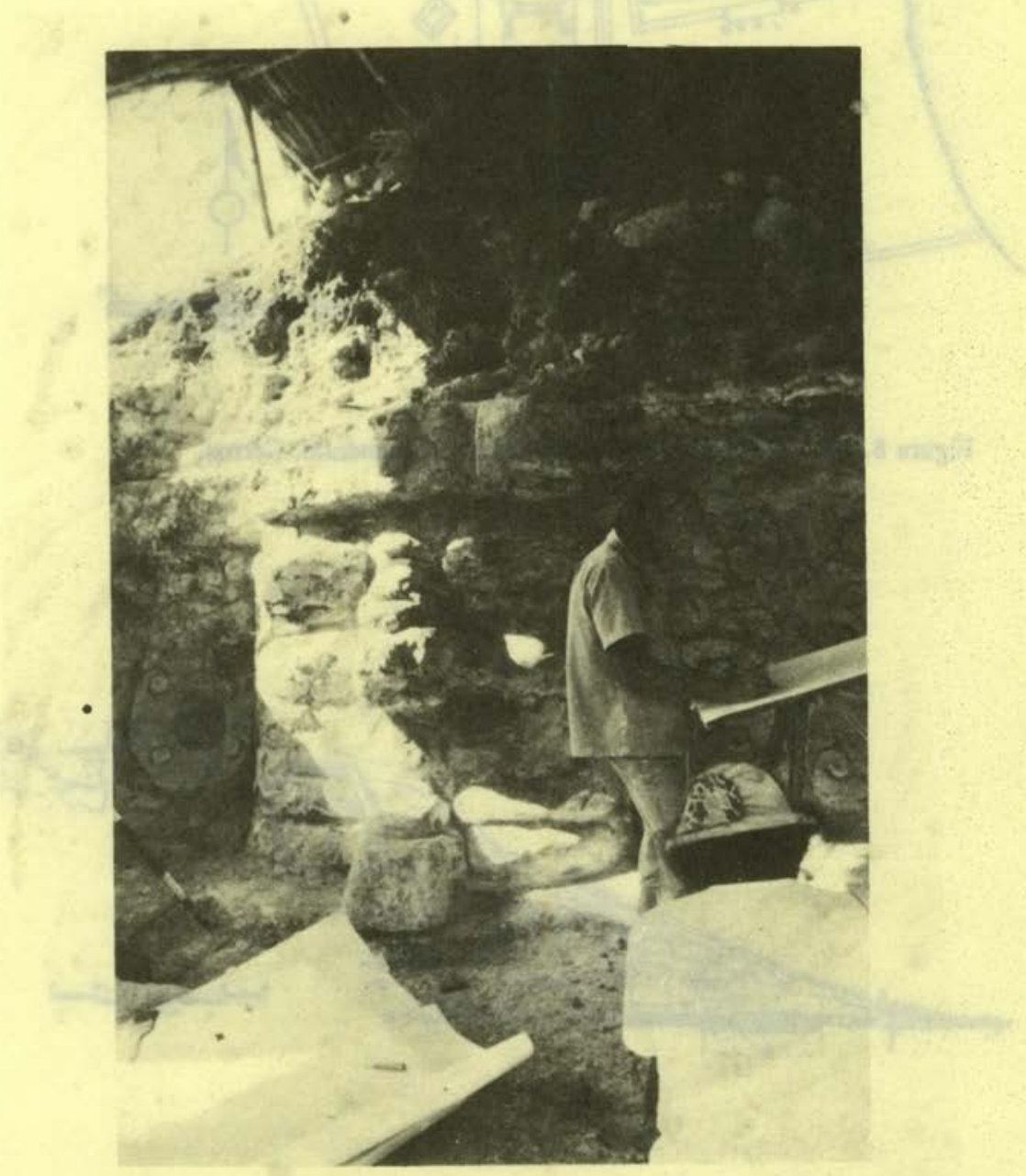

Figura 7. Mascarón policromado (inferior, izquierdo), hallado sobre la fachada sur de la Estructura 5C-segunda. Cerros. 


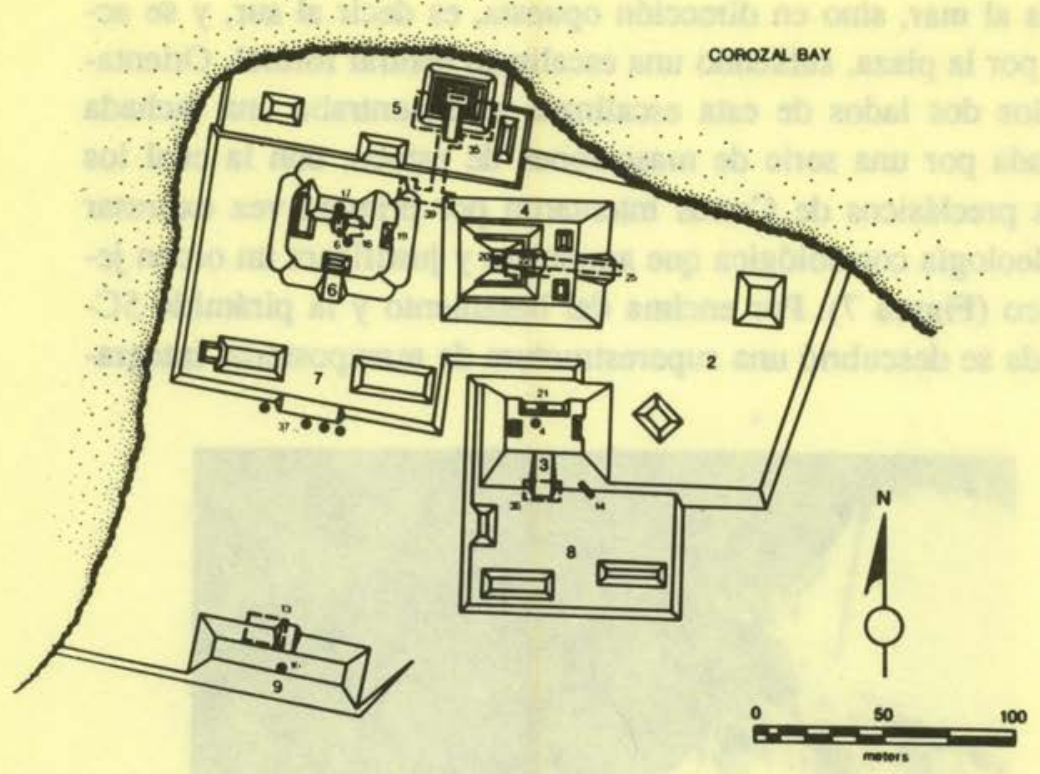

Figura 8. Mapa del recinto de arquitectura monumental, Cerros.

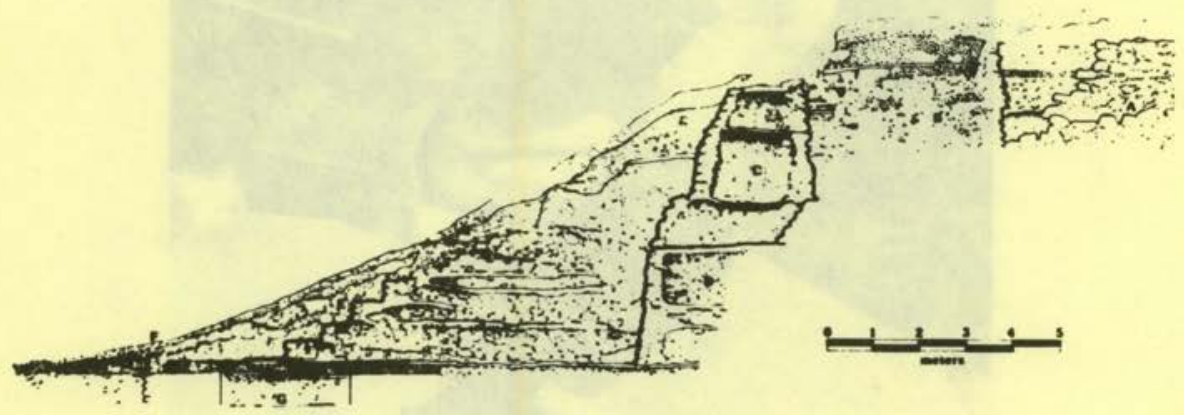

Figura 9. Técnica constructiva, Estructura 4B, Cerros. Se destacan los cajones Estudios de de piedraraya. Vol. XIX, 1992 

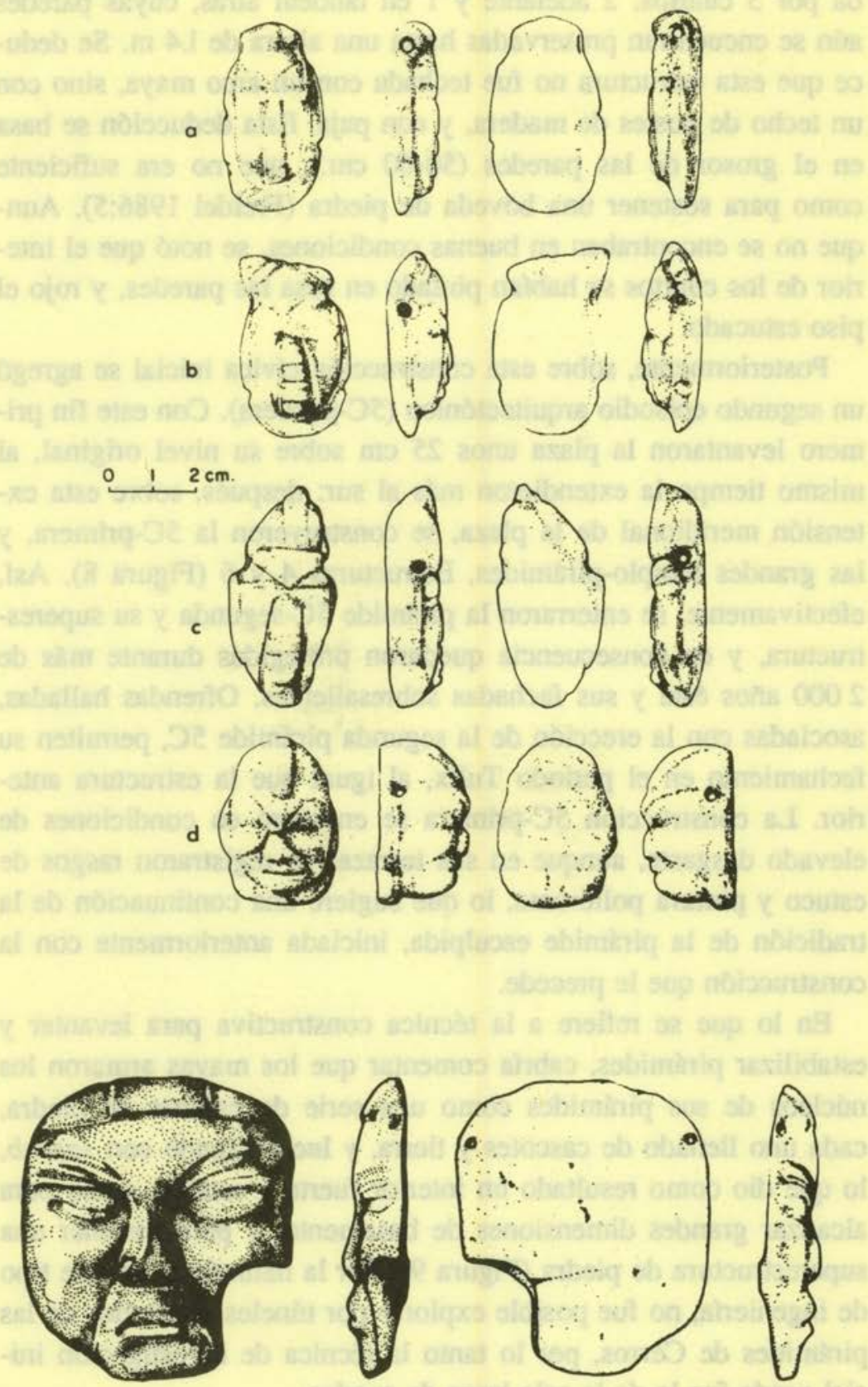

Figura 10, 11. Cinco cabezas de jade, descubiertas en una ofrenda, encima de la Estructura, 6Bal Cerros dya. Vol. XIX, 1992

Instituto de Investigaciones Filológicas/

Centro de Estudios Mayas, UNAM

ISSN 0185-2574 
da por 3 cuartos, 2 adelante y 1 en tándem atrás, cuyas paredes aún se encuentran preservadas hasta una altura de $1.4 \mathrm{~m}$. Se deduce que esta estructura no fue techada con un arco maya, sino con un techo de postes de madera, y con paja. Esta deducción se basa en el grosor de las paredes $(50-60 \mathrm{~cm}$.), que no era suficiente como para sostener una boveda de piedra (Freidel 1986:5). Aunque no se encontraban en buenas condiciones, se noto que el interior de los cuartos se habran pintado en rosa las paredes, y rojo el piso estucado.

Posteriormente, sobre esta construcción cf́vica inicial se agrego un segundo episodio arquitectónico (5C-primera). Con este fin primero levantaron la plaza unos $25 \mathrm{~cm}$ sobre su nivel original, al mismo tiempo la extendieron más al sur: después, sobre esta extensión meridional de la plaza, se construyeron la 5C-primera, y las grandes templo-pirámides, Estructuras 4 y 6 (Figura 8). Asf, efectivamente, se enterraron la pirámide $5 \mathrm{C}$-segunda y su superestructura, y en consecuencia quedaron protegidas durante más de 2000 años ésta y sus fachadas sobresalientes. Ofrendas halladas, asociadas con la erección de la segunda pirámide $5 \mathrm{C}$, permiten su fechamiento en el periodo Tulix, al igual que la estructura anterior. $\mathrm{La}$ construcción 5C-primera se encontro en condiciones de elevado desgaste, aunque en sus terrazas se registraron rasgos de estuco y pintura polf́croma, lo que sugiere una continuacion de la tradición de la pirámide esculpida, iniciada anteriormente con la construcción que le precede.

En lo que se refiere a la técnica constructiva para levantar y estabilizar pirámides, cabría comentar que los mayas armaron los núcleos de sus pirámides como una serie de cajones de piedra, cada uno llenado de cascotes y tierra, y luego tapado con sascab, lo que dio como resultado un interior fuerte y estable, como para alcanzar grandes dimensiones de basamento, y para sostener una superestructura de piedra (Figura 9). Por la naturaleza de este tipo de ingeniería, no fue posible explorar por túneles el interior de las pirámides de Cerros, por lo tanto la técnica de investigación inicial usada fue la de la cala larga de sondeo. 
La pirámide, Estructura 6, que se ubica al suroeste de la Estructura 5, representa un solo episodio constructivo, también durante la fase Tulix. Se construyó su basamento de 55 x $64 \mathrm{~m}$, hasta una altura de $7 \mathrm{~m}$, encima fue armada la pirámide, que alcanza una altura total de aproximadamente $13 \mathrm{~m}$ sobre el nivel de la tierra. Excavaciones en la cumbre de la pirámide rindieron una ofrenda integrada por 7 vasijas cerámicas provenientes del Preclásico Tardío (Robertson-Freidel 1980). Además, se descubrió un conjunto de 5 cabezas de jade, afiliadas estilísticamente con los olmecas (Freidel y Schele 1988:552); Garber 1986:118) (Figuras 10 y 11). Una de ellas, lleva el simbolismo incipiente del dios arlequin (bromista) maya, según Schele (Freidel y Schele 1988a, b; Schele y Miller 1986), por su gorro tripartita. Este dios arlequín se asocia con las escenas de poder en tiempos Clásicos.

Por una cala de sondeo que se excavó en la fachada sur de la piramide, Estructura 6, se dieron a conocer restos de 2 terrazas, aparentemente decoradas con mascarones de estuco. Esto sugiere la existencia de otra fachada similar a la de los mascarones sobre las pirámides 5C-primera y 5C-segunda. Desgraciadamente no se les pudieron conocer, porque estaban en condiciones de sumo deterioro.

La más grande de las pirámides de Cerros es la Estructura 4, que mide $68 \times 58 \mathrm{~m}$ en su base, con una altura de $10 \mathrm{~m}$. Se ubica encima de la acropolis, enfrente de las estructuras 5 y 6 . La acropolis de Cerros, que abarca una extensión de $32000 \mathrm{~m}^{2}$, equivale al doble del tamaño que presenta Tikal en la misma época (Freidel 1986). Por encima se construyo la estructura 4B, producto de un solo episodio de construcción, con orientación hacia el este, rumbo a la plaza y también a la costa. En la cima de esta pirámide truncada, los mayas cavaron una cámara hundida, probablemente para ser usada como tumba. Esta cámara estaba tapada con bóveda de piedras, uno de los primeros arcos maya conocidos (Freidel 1986). La b6veda (que se encuentra colapsada) es identificable por la presencia y la orientación de sus lajas, visibles en el pefil de la excavación. La cámara no contenía restos humanos dentro, y nun- 
ca tuvo función funeraria. Poco después de terminarla, se preparó un piso encima de la cámara hundida, sobre el cual levantaron un banco de estuco. Aunque no cuenta con un buen estado de preservacion, es aparente que la superestructura 4B destacaba por estar decorada con una fachada de yeso pintado. Un sondeo por debajo de la escalinata principal revelo una ofrenda en contexto sellado, que comprende fragmentos de vasijas Tulix, implementos de sflex, y hueso.

La estructura 4B pertenece al Preclásico Tardío, como las demás construcciones monumentales en Cerros, pero a diferencia de las otras pirámides, los residentes de Cerros en tiempos posteriores también la visitaron y la utilizaron durante el Clásico Temprano y, después, en el Postclásico Tardío. Una ofrenda ritual asociada con el banco de estuco dentro de la superestructura 4B presento artefactos del Clásico Temprano, sobre todo carbón, resina de copal, vasijas rotas, fragmentos de jade, navajillas prismáticas de obsidiana, y una serie de vasijas completas sobrepuestas. Se ha planteado un aprovechamiento de la pirámide por gente del Clásico Temprano, quienes frecuentaron el templo de sus antepasados con el fin de mantener la práctica de sus ritos tradicionales. También en la cumbre de esta pirámide se encontraron las ruinas de una estructura perecedera, asociada a una ofrenda de incensarios y otros artículos diagnósticos del Postclásico Tardío. En fin, la Estructura 4 es una pirámide del Preclásico Tardío, con utilización efímera durante los inicios del Clásico, y con una modificación y aprovechamiento Postclásico.

Aunque la mayor parte de la arquitectura monumental en Cerros está concentrada en un conjunto al lado del mar, también se encuentra presente en baja frecuencia tierra adentro. Un ejemplo es la pirámide 29B, a una distancia de $300 \mathrm{~m}$ al sureste del centro ceremonial de Cerros. Se fecha más reciente que la arquitectura monumental en la costa, pero todavía se considera dentro de la fase Tulix (Freidel 1981). Es en una pirámide aislada, erigida sobre la extensión oriental de una amplia plataforma rectangular. Su basamento mide $38 \times 44 \mathrm{~m}$, sobre el cual la pirámide alcanza una 


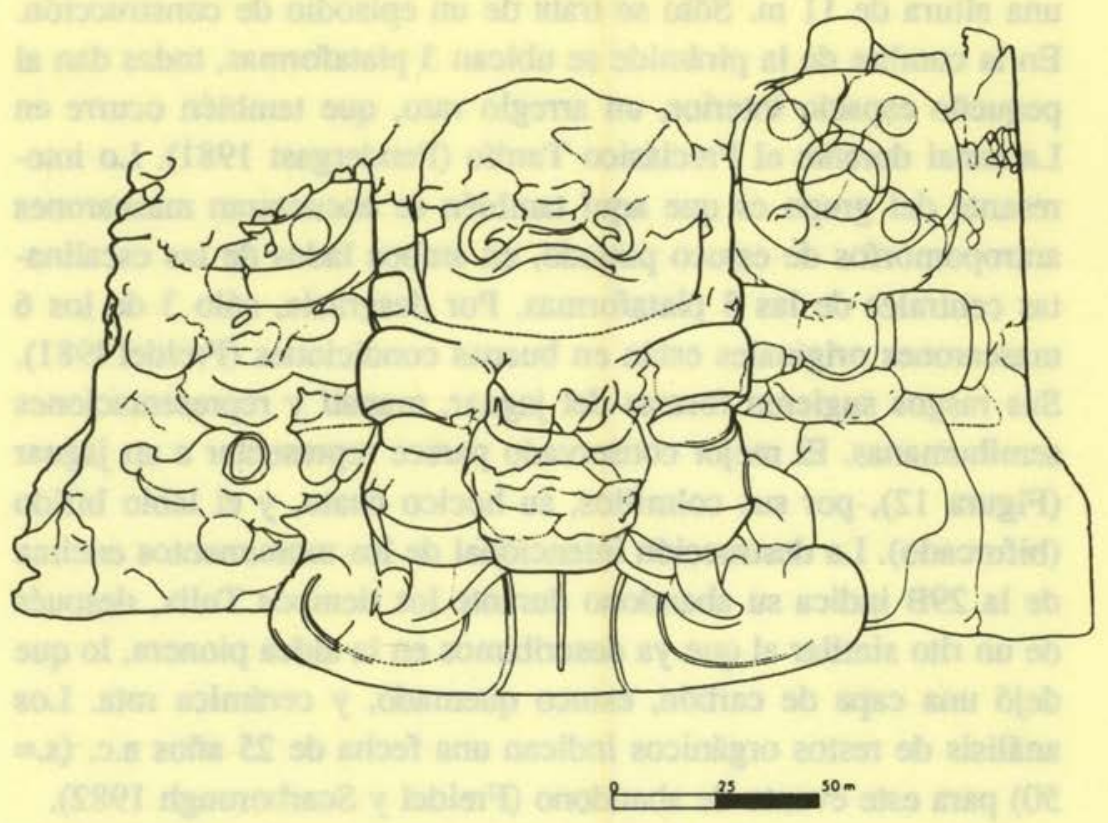

Figura 12. Mascaron estucado con forma de jaguar. Estructura 29B, Cerros.
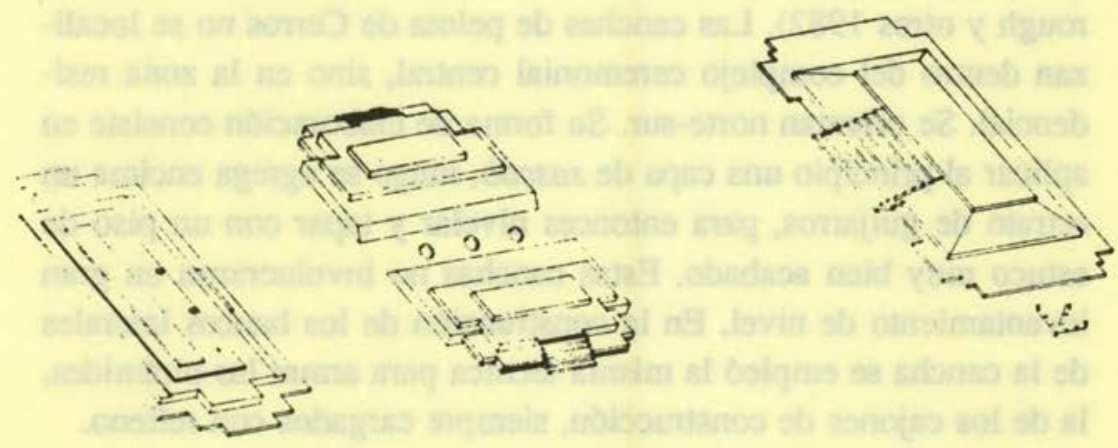

Figura 13. Juego de pelota, Estructura 50, Cerros. 
una altura de $11 \mathrm{~m}$. S6lo se trata de un episodio de construcción. En la cumbre de la pirámide se ubican 3 plataformas, todas dan al pequeño espacio interior, un arreglo raro, que también ocurre en Lamanai durante el Preclásico Tardío (Pendergast 1981). Lo interesante del grupo es que aquí también se encuentran mascarones antropomorfos de estuco pintado, en ambos lados de las escalinatas centrales de las 3 plataformas. Por desgracia, s6lo 3 de los 6 mascarones originales están en buenas condiciones (Freidel 1981). Sus rasgos sugieren formas del jaguar, manatr y representaciones semihumanas. El mejor conservado parece representar a un jaguar (Figura 12), por sus colmillos, su hocico chato, y el labio bffido (bifurcado). La destrucción intencional de los monumentos encima de la 29B indica su abandono durante los tiempos Tulix, después de un rito similar al que ya describimos en la aldea pionera, lo que dejo una capa de carbón, estuco quemado, y cerámica rota. Los análisis de restos orgánicos indican una fecha de 25 afios a.c. (s.= 50) para este evento de abandono (Freidel y Scarborough 1982).

En la zona maya los juegos de pelota se consideran un fenomeno del Clásico Tardío. Previo a este periodo son raros. Por ello, el descubrimiento de 2 canchas de pelota que corresponden a la fase Tulix (entre 100 a.c. y 100 d.c.), podrian hablar de las más antiguas conocidas hasta hoy día en las tierras bajas mayas (Scarborough y otros 1982). Las canchas de pelota de Cerros no se localizan dentro del complejo ceremonial central, sino en la zona residencial. Se orientan norte-sur. Su forma de elaboración consiste en aplicar al principio una capa de sascab, luego se agrega encima un estrato de guijarros, para entonces nivelar y tapar con un piso de estuco muy bien acabado. Estas canchas no involucraron un gran levantamiento de nivel. En la construcción de los bancos laterales de la cancha se empleó la misma técnica para armar las pirámides, la de los cajones de construccion, siempre cargados con relleno.

En Cerros, el juego de pelota más grande, más formal y mejor elaborado fue la Estructura 50, que al principio se interpret6 como una unidad residencial de 4 estructuras pequefias que compartieron, a su vez, una pequeña plaza central (Figura 13). S6́lo cuando 
quedo claro, durante las excavaciones, que la plaza compartida manifiesta una pendiente que sube al este y al oeste, se interpreto la funcion ceremonial de este grupo arquitectónico. Su exploración dio como resultado la exposición de casi $400 \mathrm{~m}^{2}$. de la cancha y sus estructuras circundantes. Encontramos 2 pisos de cancha superpuestos, o sea una superficie inicial y su modificación posterior. La cancha misma mide $4.2 \mathrm{~m}$ de ancho. Aunque no se pudieron encontrar los marcadores tradicionales para el juego de pelota, se descubrieron 3 hoyos ovalados, respectivamente, en el norte, centro, y sur de la cancha. Se supone que los habitantes de Cerros le quitaron los marcadores al fin de la ocupación Tulix. Las 2 estructuras laterales (los bancos de la cancha) presentan una forma rectangular. Miden $18 \mathrm{~m}$ de largo, y alcanzan una altura de $2.1 \mathrm{~m}$. Estas construcciones laterales llevan bancos con pendientes, o sea, los muros del juego de pelota, que aparentemente habfan sido decorados con estuco y luego pintados. Al menos durante el Preclásico Tardío estas estructuras laterales carecfarı de superestructuras, conclusion indicada por la falta de huellas de postes $u$ otra evidencia de construcción por encima.

En los extremos norte y sur de la plataforma Estructura 50 se ubicaron estructuras sin asociación directa con la cancha de pelota. La 50B, al límite norte de la cancha, parece haber sido un pequeño templo. Al sur del grupo, la forma rectangular de la estructura 50D sugiere que se trata de uno de los llamados "palacios" mayas. La escalinata de la 50D da al norte, y hubiera permitido una buena visión a los juegos de pelota que se realizaron sobre la cancha. De hecho, se plantea para ella una función de auditorio para las ceremonias del juego de pelota (Scarborough y otros 1982). Atrás de la 50D se colinda directamente sobre el canal de drenaje. Aparte de su posible función ceremonial, es posible que la estructura 50D haya sido aprovechada como vivienda de élite, durante tiempos Tulix o en el Clásico Temprano, con base en las acumulaciones de restos domésticos recuperados durante excavaciones en su esquina sureste (Lewenstein 1987).

El segundo juego de pelota en Cerros, la Estructura 61, también 
cuenta con 2 pisos de estuco duro, sobrepuestos. Se recupero aquí un depósito sellado de cerámica Tulix. Igual que 1a 50, el juego de pelota, Estructura 61, también tiene bancos laterales con pendientes, estucados y pintados en rojo. S6́lo las dos estructuras laterales integran el grupo 61, la cancha quedó abierta en sus extremos norte y sur. Aqui abrimos 3 calas de sondeo, hasta una extension de $100 \mathrm{~m}^{2}$. La cancha misma mide $4.1 \mathrm{~m}$ de ancho, por $20 \mathrm{~m}$ de largo, norte-sur, según la longitud de los edificios laterales. Estos bancos del juego de pelota alcanzaban unos $2.7 \mathrm{~m}$ de altura, y se caracterizan por una escalinata que da al exterior del grupo. Encima de los bancos no se encontró ninguna evidencia de superestructuras. Tampoco se recuperaron en la Estructura 61 los marcadores del juego, sino un solo hoyo circular (con diámetro de $\mathbf{1 . 6 5}$ m) en la cancha, lo que indica un marcador supuestamente llevado durante el Preclásico Tardío, quizá en el momento del abandono del sitio.

\section{Una interpretación iconográfica de Cerros}

Comentan Schele y Miller (1986:86) acerca de la estela 29 de Tikal, fechada en 292 d.c., a la que consideran como el inicio del periodo Clásico en las tierras bajas mayas: "Con la excepción de la aparición de las estelas, todos los elementos que caracterizan la civilización maya, ya se encontraban durante el Preclásico terminal", o sea en el primer siglo antes de Nuestra Era. Fue durante el Preclásico Terminal que se establecieron la cosmovisión maya y la pauta del rey que permaneció por todo el periodo Clásico. El registro arqueológico de Cerros indica crecimiento demografico, expansiones comerciales, la concentración de influencia en manos de ciertos individuos, o en un solo linaje. En consecuencia, por el 50 a.c. Cerros ya no era una comunidad económicamente igualitaria. Los cambios rápidos que acabamos de revisar en las condiciones sociales de la población, introdujeron en la comunidad ciertas contradicciones que luego llegaron a nivel de crisis social (Freidel y 
Schele 1988b). Los dirigentes buscaron una manera de resolver esta crisis social, considerando tres formas de solucion:

- un cambio de las condiciones, o retorno al estado previo, la sociedad igualitaria; 0

-el colapso del sistema; 0

- la transformación del modelo de la realidad igualitaria para que se adecúe con el nuevo orden de la realidad: el elitismo.

Fue la tercera opción la que funciono. Tomando a Cerros como ejemplo, el proceso de transformación se llevó a cabo a través de la creación de grandes piramides estucadas, que anunciaron simbolicamente al público y celebraron la nueva autoridad jerárquica y su respaldo, las sanciones cosmicas. Asf, aparecieron por primera vez los elementos de la iconografia que permanecieron por todo el periodo Clásico.

Esta política de manejo del arte público por medio de la arquitectura esculpida se manifiesta no sólo en Cerros, sino coetáneamente en otros sitios en las tierras bajas mayas, en Acanceh (Marquina 1964, Quintal 1988), Tikal (Wm. Coe 1965), El Mirador (Matheny 1980), Lamanai (Pendergast 1981), y Uaxactún (Ricketson y Ricketson 1937). Allf se encuentran algunas de las pirámides más altas de la América precolombina, que alcanzan alturas de $50 \mathrm{~m}$ en El Mirador (Schele y Miller 1986, Matheny 1980, Dahlin 1984). Los arquitectos y escultores mayas del Preclásico Tardío manipularon este medio arquitectónico con el fin de redefinir simbolicamente la realidad social y generar y mantener la unidad (cohesión) social del pueblo. Usaron elementos de la ideologia básica del pueblo, el Sol y el planeta Venus, y el mito de los gemelos héroes, Hunahpú y Xbalamqué, el planeta Venus y el Sol, transformándolos para que la aparición de una clase de élite se viera como el orden natural del mundo. Es decir, que el nuevo sistema fuera ordenado y mantenido por los dioses. Una vez puesto y aceptado, esta metafora del. rey como fuerza pivote de la naturaleza quedo como punto clave en la ideoglogia maya por los subsecuentes 1000 afios (Schele y Miller 1986).

Fue durante la temporada de 1977 en el campo que se descu- 

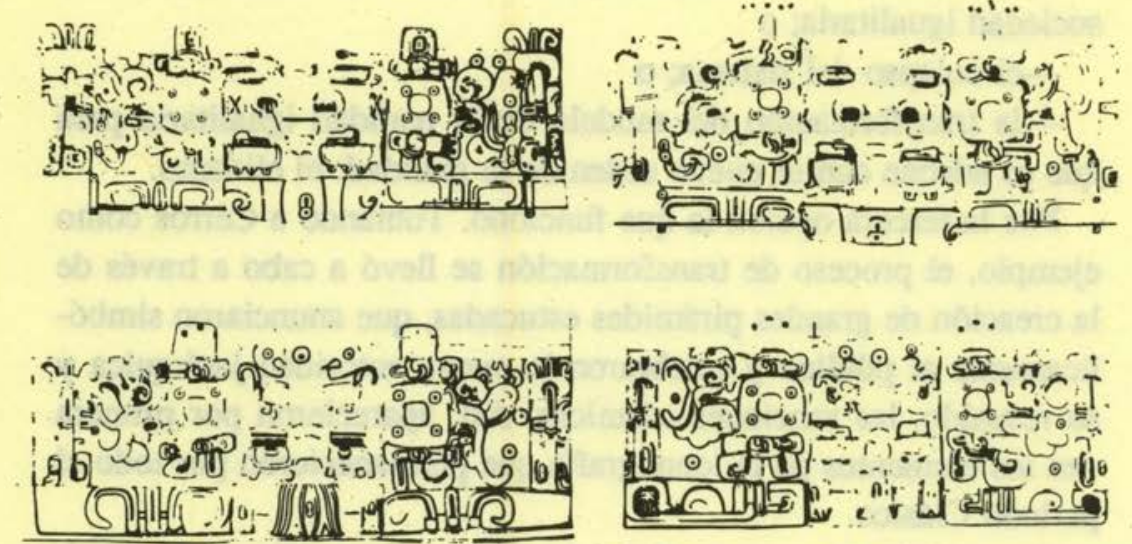

Figura 14. Reconstrucción de los cuatro mascarones que integran la fachada sur de la Estructura 5C-segunda, Cerros.

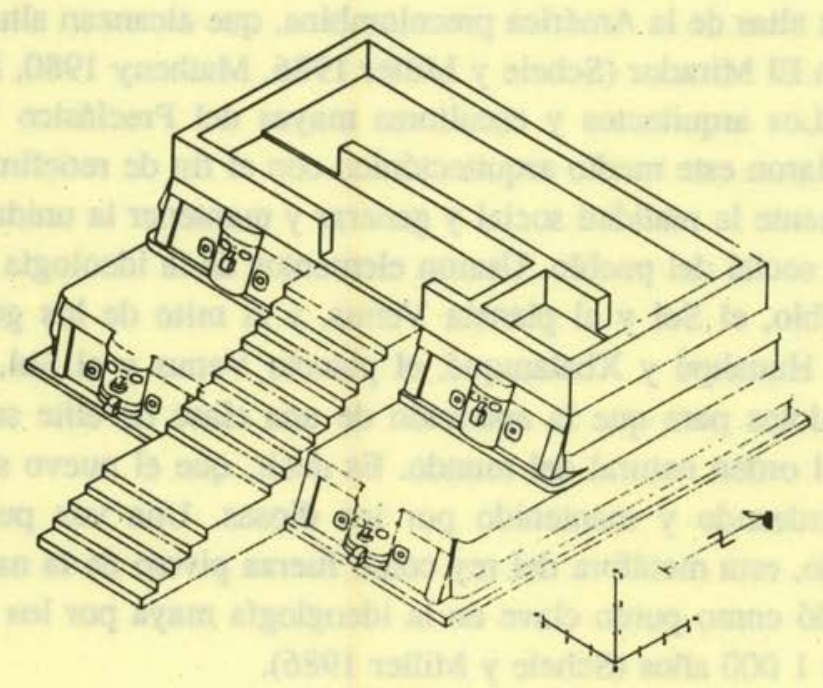

Figura 15. Arreglo, fachada sur de la Estructura 5C-segunda, Cerros. 
brio el primero de los cuatro mascarones zoomorfos que se encuentran en buenas condiciones sobre la fachada sur de la pirámide 5C-segunda. Nos impresiono por sus rasgos semihumanos, por elementos que recuerdan el arte Izapa, y por los diagnosticos de la indumentaria de los reyes mayas clásicos. Entre ellos destacan el cartucho con el glifo kin (Freidel 1977). Subsecuentemente se nos presentaron 3 mascarones adicionales. Dos se ubican al oeste y otros dos al este de la escalinata central que daba a la cumbre de la pirámide. Las imágenes se elaboraron por el modelaje en estuco, sobre la superficie de la fachada, en la cual se habfa metido piedras, las que se extienden por adelante y que forman las mejillas, narices, y hocicos de los 4 personajes. Los 2 mascarones de abajo llevan hocicos chatos, los de arriba, hocicos y labios alargados, como de cocodrilo (Figura 14). El descubrimiento de estos 4 mascarones y otro similar, en la estructura 29B (Freidel (1986), impulsó un estudio iconografico por parte de Freidel, en el que solicitó la colaboración de la historiadora del arte maya, Linda Schele.

La interpretación dada considera la pirámide $5 \mathrm{C}$-segunda como un espacio escénico, y los mascarones y el sacerdote-rey de Cerros como los personajes, 0 actores. Los dos mascarones inferiores, los que llevan el hocico chato, y el glifo kin sobre sus mejillas, representan al Jaguar-Sol, Xbalamqué, y el Sol del amanecer, así como del crepúsculo. Los mascarones superiores llevan hocicos y labios largos, como el cocodrilo o saurio. Estos representan al planeta Venus, o al Gemelo mayor, Hunaphú.

Desde el auditorio, abajo en la plaza, el agricultor maya tenía un escenario que dramatiza el elemento básico del ciclo calendárico, el pasaje de cada día. En la madrugada se ve saliendo, atrás de la piramide, a Venus, primero del Caribe, y jalando al Sol por el cielo. En la tarde desaparece el Sol por el horizonte, con Venusestrella vespertina, siguiéndolo. Los dos bajan al inframundo (debajo del mar), para volver a salir al día siguiente. Este ciclo natural se repite en el arreglo de los cuatro mascarones sobre la pirámide. A la derecha (en la mañana) se ve a Venus (mascaron supe- 
rior) saliendo, seguido por el Sol (mascaron inferior). En la tarde, a la izquierda desaparece Venus (mascaron superior) por el horizonte, tras el Sol (mascaron inferior). Asi, la iconografía de la fachada esculpida duplica a la naturaleza (Figura 15). El lider de Cerros solo por subir la escalinata central hasta la cumbre de la pirámide, aparenta ser el pivote o fuerza causante que controla y perpetúa este orden del universo.

Así, la presencia del líder en el centro de la escena, le brindaba autoridad por asociación. Este simbolismo se desarrolla en tiempos preclásicos, primero con representaciones de mascarones abstractos. En Cerros vemos una forma temprana de esta cosmovision. Después sus elementos se transforman para convertirse en las características diagnósticas de los reyes del Clásico. Por ejemplo, entre ellas destacan:

- Los mascarones superiores que llevan una corona con tres elementos, parecidos a hojas. Schele plantea que este rasgo es un prototipo del gorro del dios "arlequín", lo que posteriormente se convierte en la corona del rey maya (Freidel y Schele 1988b);

- Los mascarones inferiores llevan el glifo kin sobre las mejillas. Asociado con los reyes del Clásico, también simboliza al Sol, y a Hunahphú, el Jaguar-Sol.

- Los cuatro mascarones llevan orejeras grandes, que sobresalen por sus cuatro puntitos, en las cuatro direcciones cardinales (el patrón quincunx) (Figura 16). Están acompanadas por dos nudos, uno por encima y otro por debajo: otro rasgo del rey maya del Clásico (Freidel y Schele 1988a).

Buena parte de la indumentaria y omamentación tradicional que se asocian con la institucionalización del reinado maya (el ahaw), tienen su origen en el simbolismo del Preclásico Tardío. Las dinastras del Clásico, por su manejo de estos símbolos, hicieron hincapié en sus lazos de parentesco, reales y míticos, con las primeras élites mayas, las del Preclásico Tardío.

De sus formas iniciales abstractas, este simbolismo, que celebra y justifica la sociedad de élite, se convierte en imágenes cada vez más realistas. Se transformaban en retratos de los gobernantes 


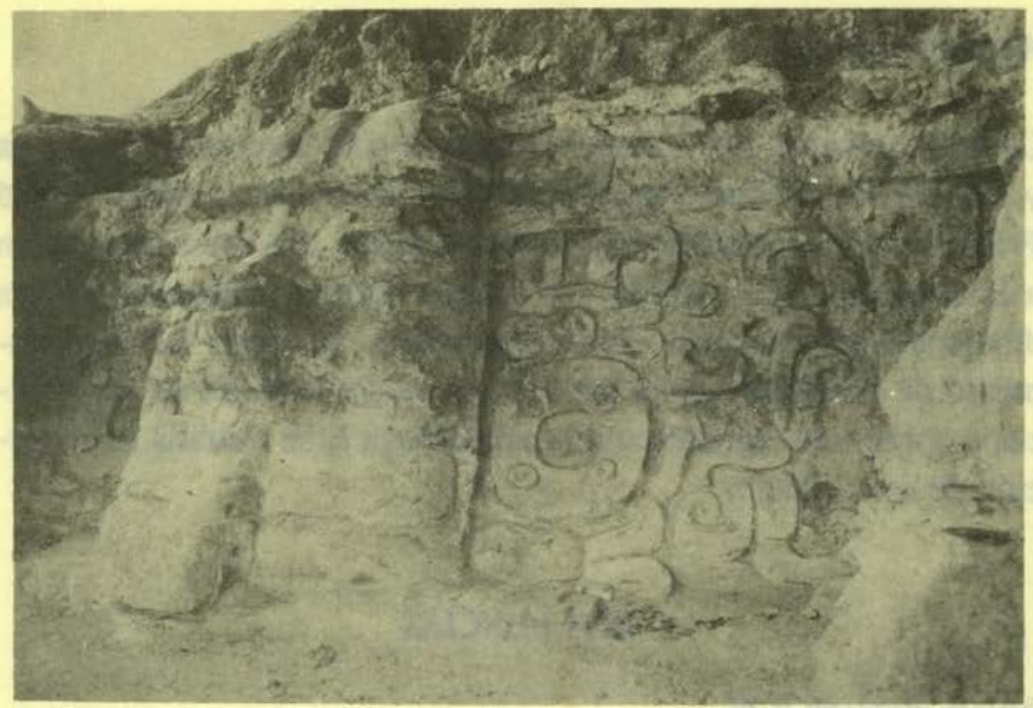

Figura 16. Mascarón inferior, izquierdo, 5C-segunda, Cerros. N6́tese la orejera, con su nudo por encima.

mismos, un ejemplo de lo cual se encuentra en los mascarones menos antiguos de Kohunlich (Andrews 1987, Segovia 1968). Por fin, se discontinúan estas imágenes, al transformarse en el culto de las estelas (Freidel y Schele 1988b).

En este momento la transformación social ya está hecha.

Ahora se ha establecido la legitimización de la clase de élite y la institución del ahaw. Su poder y autoridad se basan en los líderes mismos, ya que son aceptados como los representantes encarnados de los antepasados de todos los mayas, y los intermediarios con las fuerzas del universo.

En resumen, los nuevos datos del Preclásico maya evidencian las primeras etapas en el proceso de estratificación de la sociedad maya. En Cerros y en otros centros contemporáneos, vemos cómo evolucionó la sociedad preclásica, en tomo a su demografía y complejidad sociopolítica, y como una élite emergente explotó el arte monumental, para legitimizarse y justificar un cambio en el orden social, de una sociedad igualitaria, a otra formalmente jerarquizada. 
Agradecimientos

La realización de este trabajo no hubiera sido posible sin las ideas y labores de muchos companieros, principalmente el doctor David Freidel y los integrantes del Proyecto Cerros. Las fotos pertenecen a la colección de la autora; los dibujos fueron realizados por los dibujantes del Proyecto Cerros. Agradezco el apoyo del Departamento de Fotografia de la ENAH por su preparación de las graficas y sobre todo agradezco a la arqueóloga Elba Estrada su redacción de este trabajo.

\section{REFERENCIAS}

ADAMS, RichaRD E.W.

1986 "Rio Azul: Lost City of the Maya". National Geographic 169:(4):420-451.

ANDREWS, GEORGE F.

1985 “Architecture at Kohunlich, Quintana Roo, México. A Preliminary Report". Cuadernos de Arquitectura Mesoamericana 10:17-32.

ASHMORE, WENDY

1981 "Some Issues of Method and Theory in Lowland MayaSettlement Archaeology". En Lowland Maya Settlement Patterns, ed. por W. Ashmore. pp. 37-69. University of New Mexico Press, Albuquerque.

BRONSON, BENNET

1965 "Roots and the Subsistence of the Ancient Maya". Southwestern Journal of Anthropology 22:251-279.

Carr, Helen Sorayya

1986 "Preliminary Results of Analysis of Fauna". En Archaeology at Cerros, Belize, Central America: Volume 1, An Interim Report. ed. por Robin A. Robertson y David A. Freidel. Southern Methodist University Press, Dallas, pp. 127 146.

Cluff, Maynard

1982 Lowland Maya Nucleation: A Case Study from Northern Belize. Tesis de doctorado, Southern Methodist University, Dallas. University Microfilms, Ann Arbor. 
1986 "Excavations in the Late Preclassic Nucleated Village". En Archaeology at Cerros, Belize, Central America: Volume 1, An Interim Report. ed. por Robin A. Robertson y David A. Freidel. Southern Methodist University Press, Dallas, pp. 45-63.

1988 "Domestic Architecture and Origins of Complex Society at Cerros". En Household and Community in the Mesoamerican Past. Ed. por Richard R. Wilk y Wendy Ashmore. University of New Mexico Press, Albuquerque, pp. 199225.

Com, Michari D. y Richard A. DieHL.

1980 In the Land of the Olmec. University of Texas Press, Austin.

Cов, Wицам

1965 "Tikal: Ten Years of Study of a Mayan Ruin in the Lowlands of Guatemala". Expedition 8:1:5-56.

Crane, Cathy

1986 "Late Preclasic Maya Agriculture, Wild Plant Utilization, and Land-Use Practices". En Archaeology at Cerros, Belize, Central America: Volume 1, An Interim Report. Ed. por Robin A. Robertson y David A. Freidel. Southern Methodist University Press, Dallas, pp. 147-164.

DAHLIN, BrUCE H.

1979 "Cropping Cash in the Proto-Classic: A Cultural Impact Statement". Bn Maya Archaeology and Ethnohistory, ed. por N. Hammond y G. R. Willey. University of Texas Press, Austin, pp. 21-37.

1984 "A Colossus in Guatemala: The Preclassic Maya City of El Mirador". Archaeology 37 (6):18-25.

1985 "La geografía histórica de la antigua agricultura maya". En Historia de la agricultura: Epoca prehispánica-Siglo XVI. Ed. por Teresa Rojas, Rabiela y William T. Sanders. Colección Biblioteca del INAH México, pp. 197-214.

Fremel, David A.

1976 "Cerro Maya: A Late Preclassic Center in Corozal District". En Recent Archaeology in Belize. Ed. por R. Buhler, S. J. pp. 73-99. Belize Institute for Social Research and Action, Belize City, Belize. Occasional Paper No. 3.

1977 "A Late Preclassic Monumental Mask at Cerros, Northern Belize". Journal of Field Archaeology 4:488-491. 
1978 "Maritime Adaptation and the Rise of Maya Civilization: The View from Cerros, Belize". En Prehistoric Coastal Adaptations. Ed. por B. L. Stark y B. Voorhies. Academic Press, New York, pp. 239-265.

1979 "Culture Areas and Interaction Spheres: Contrasting Approaches to the Emergence of Civilization in the Maya Lowlands". American Antiquity 44:36-54.

1981 "Civilization as a State of Mind: The Cultural Evolution of the Lowland Maya". En The Transition to Statehood in the New World. Ed. por Grant D. Jones. Cambridge University Press, New York, pp. 188-227.

1986 "The Monumental Architecture". En Archaeology at Cerros, Belice, Central America: Volume 1, An Interim Report. Ed. por Robin A. Robertson y David A. Freidel. Southern Methodist University Press, Dallas, pp. 1-21.

Freidel, David A., Robin Robertson, y Maynard B. Cuffr

1982 "The Maya City of Cerros". Archaeology 35 (4):12-21.

Freidel, David A., y Vernon Scarborough

1982 "Subsistence, Trade, and Development of the Coastal Maya". En Maya Subsistence: Studies in Memory of Dennis E. Puleston. Ed. por K.V. Flannery. Academic Press, New York, pp. 131-151.

Freidel, DAVID A., Y LINDA SCHELE

1988a "Kingship in the Late Preclassic Maya Lowlands: The instruments and Places of Ritual Power". American Anthropologist 90:547-567.

1988b "Symbol and Power: A History of the Lowland Maya Cosmogram". En Maya Iconography. Ed. por Elizabeth P. Benson y Gillett G. Griffin. Princeton University Press, Princeton, pp. 44-93.

GARBER, JAMES F.

1983 "Patterns of Jade Consumtion and Disposal at Cerros, Northern Belize". American Antiquity 48 (4):800-807.

1986 "The Artifacts". En Archaeology at Cerros, Belize, Central America: Volume 1, An Interim Report. Ed. por Robin A. Robertson y David A. Freidel. Southem Methodist University Press, Dallas, pp. 117-126.

GIFFORD, JAMES C.

1976 Prehistoric Pottery Analysis and the Ceramics of Barton Ramie in the Belize Valley. Memoirs of the Peabody Mu- 
seum of Archaeology and Ethnology, 18. Harvard Univer-

HAMMOND, NORMAN sity, Cambridge.

1982 "Unearthing the Oldest Known Maya". National Geographic 165:127-140.

Harrison, Peter D. y B. L. TURner II

1978 "Implications from Agriculture for Maya Prehistory". En Harrisson y Turner II, ed., Pre-Hispanic Maya Agriculture. University of New Mexico Press, Albuquerque, pp. 337 373.

harrison, Peter D. y B. L. TURner II (eDs.)

1978 Pre-Hispanic Maya Agriculture, University of New Mexico Press, Albuquerque.

Hester, Thomas R.

1985 "The Maya Lithic Sequence in Northern Belize". En Stone Tool Analysis. Ed. por Mark G. Plew, James C. Woods, y Max G. Pavesic. University of New Mexico Press, Albuquerque, pp. 187-210.

Hester, Thomas R. y HarRY J. Shafer

1984 "Explotation of Chert Resources by the Ancient Maya of Northern Belize, Central America". World Archaeology 16(2):157-173.

KOSAKOWSKY, LAURA J.

1987 Preclassic Maya Pottery at Cuello, Belize. Anthropological Papers of the University of Arizona, No. 47, University of Arizona Press, Tucson.

LAMBERT, JOHN Y THOR ARNASON

1978 "Distribution of Vegetation on Maya Ruins and its Relationship to Ancient Land-Use at Lamanai, Belize". Turrialba 28:33-41.

LEWENSTEIN, SUZANNE

1982 "Woodworking Tools at Cerros". Ponencia presentada en la Segunda Conferencia Sobre la Lítica Maya, organizada por Thomas Hester y Harry Shafer. San Antonio, Texas, octubre de 1982.

1986 "Feature 11 and the Quest for the Elusive Domestic Structure: A Preliminary Reconstruction Based on Chipped Stone Use". En Archaeology at Cerros, Belize, Central America: Volume l: An Interim Report. Ed. por Robin A. Robertson y David A. Freidel. Southem Methodist Press, Dallas, pp. 65-73. 
1987 Stone Use at Cerros: The Ethnoarchaeological and UseWear Evidence. University of Texas Press, Austin.

MACNEISH, RichARD

1981 Second Annual Report of the Belize Archaic Archaeological Reconnaissance. Robert S. Peabody Foundation, Phillips Academy, Andover, Massachusetts.

marquina, Ignacio

1964 Arquitectura prehispánica. 2a. edición. INAH-SEP, México.

MATHENY, RAY

1980 El Mirador, Peten, Guatemala: An Interim Report. Papers of the New World Archaeological Foundation, No. 45. Brigham Young University, Provo, Utah.

Ochoa, Lorenzo y ERnesto Vargas

1985 "Informe del reconocimiento arqueológico. realizado en la cuenca del río Candelaria, Campeche". Estudios de Cultura maya, XVI:325-376.

Pendergast, David M.

1981 "Lamanai, Belize: Summary of Excavation Results, 19741980". Journal of Field Archaeology, 8:29-53.

Pring, Duncan

1977 The Preclassic Ceramics of Northern Belize. Tesis doctoral, Universidad de Londres, University Microfilms, Ann Arbor.

Pohl, Mary y Lawrence Feldman

1982 "The Traditional Role of Women and Animals in Lowland Maya Economy". En Kent Flannery, ed., Maya Subsistence: Studies in Memory of Dennis E. Puleston. Academic Press, New York, pp. 295-311.

Puleston, Dennis E.

1978 "Terracing, Raised Fields, and Tree Cropping in the Maya Lowlands: A New Perspective on the Geography of Power". En Pre-Hispanic Maya Agriculture. Ed. por Peter D. Harrison y B. L. Turner II. University of New Mexico Press, Albuquerque, pp. 225-245.

Quintal Suaste, Beatriz

1988 "Acanceh". En, Guía oficial: norte de Yucatán. INAHSALVAT, México, pp. 77-85.

RiCKETSON, O. G. Y E. B. RickETSON

1937 Uaxactun, Guatemala: Group E-1926-1931. Carnegie Institute, Washington, Pub. 477. 
ROBERTSON, ROBIN A.

1983 "Functional Analysis and Social Process in Ceramics: the Pottery from Cerros, Belize". En Civilization in the Ancient Americas: Essays in Honor of Gordon R. Willey. Ed. por R. M. Leventhal y A. L. Kolata. University of New Mexico Press, Albuquerque. pp. 105-142.

1986 "The Ceramics". En Archaeology at Cerros, Belize, Central America: Volume I, An Interim Report. Ed. por Robin A. Robertson y David A. Freidel. Southern Methodist University Press, Dallas, pp. 89-103.

ROBERTSON-FrEIDEL, RoBIN A.

1980 The Ceramics from Cerros: a Late Preclassic Site in Northern Belize. Tesis de doctorado, Department of Anthropology, Harvard University.

Rojas, Teresa

1985 "La tecnología agrícola mesoamericana en el siglo XVI". En Historia de la agricultura: Epoca prehispánica-Siglo XVI. Ed. por Teresa Rojas Rabiela y William T. Sanders. Colección Biblioteca del INAH, México, pp. 129-213.

SCARBOROUGH, VERNON

1980 The Settlement System in a Late Preclassic Maya Community: Cerros, Northern Belize. Tesis de doctorado, Southern Methodist University, Dallas.

1983 "A Preclassic Maya Water System". American Antiquity 48:720-744.

Scarborough, Vernon, Beverl y Mrtchum, Sorayya Carr, y David

FreIDEL

1982 "Two Late Preclassic Ballcourts at the Lowland Maya Center of Cerros, Northern Belize". Journal of Field Archaeology 9:21-34.

SCARBorough, VERNON y RoBIn RoBERTSON

1986 "Civic and Residential Settlement at a Late Preclassic Maya Center". Journal of Field Archaeology 13 (2):155175.

SChele, Linda y Mary Ellen Miller

1986 The Blood of Kings: Dynasty and Ritual in Maya Art. Kimball Art Museum, Fort Worth.

Segovia, Victor

1968 "Kohunlich". Boletín del INAH, No. 37, Epoca I:1-8. México. 
SIDRYS, RAYMOND Y JOHN ANDRESEN

1976 "Metate Import in Northern Belize". En Maya Lithic Studies: Papers from the 1976 Belize Field Symposium. Ed. por T. R. Hester y N. Hammond. Center for Archaeological Research, University of Texas at San Antonio, Special report No. 4. pp. 177-190.

SMTth, ROBERT E.

1955 Ceramic Sequence at Uaxactun, Guatemala, Volumes 1 and 2. Middle American Research Institute, Publication 20. Tulane University, New Orleans.

WIIK, RICHARD R.

1983 "Little House in the Jungle: The Causes of Variation in House Size Among Modern Kekchi Maya". Journal of Anthropological Archaeology 2:99-116.

WeAver, Muriel Porter

1981 The Aztecs, Maya, and their Predecessors: Archaeology of Mesoamerica. 2a. edición. Academic Press, New York.

Wing, ElizaBeth

1981 "A Comparison of Olmec and Maya Foodways". En The Olmec and Their Neighbors: Essays in Memory of Matthew W. Stirling. Ed. por E. P. Benson. Dumbarton Oaks, Washington, D.C., pp. 20-28.

Wright, A. C. S., D. H. Romney, R. H. Arbuckie, y V. E. Vial

1959 Land in British Honduras: Report of the British Honduras Land Use Survey Team. Her Majesty's Stationary Office, London. 